\title{
Central Appalachian Understory Red Spruce (Picea rubens Sarg.) Growth Rates and Allometric Relationships
}

Joseph M. Gray

jmg0071@mix.wvu.edu

Follow this and additional works at: https://researchrepository.wvu.edu/etd

Part of the Forest Management Commons

\section{Recommended Citation}

Gray, Joseph M., "Central Appalachian Understory Red Spruce (Picea rubens Sarg.) Growth Rates and Allometric Relationships" (2020). Graduate Theses, Dissertations, and Problem Reports. 7861.

https://researchrepository.wvu.edu/etd/7861

This Thesis is protected by copyright and/or related rights. It has been brought to you by the The Research Repository @ WVU with permission from the rights-holder(s). You are free to use this Thesis in any way that is permitted by the copyright and related rights legislation that applies to your use. For other uses you must obtain permission from the rights-holder(s) directly, unless additional rights are indicated by a Creative Commons license in the record and/ or on the work itself. This Thesis has been accepted for inclusion in WVU Graduate Theses, Dissertations, and Problem Reports collection by an authorized administrator of The Research Repository @ WVU. For more information, please contact researchrepository@mail.wvu.edu. 


\title{
Central Appalachian Understory Red Spruce (Picea rubens Sarg.) Growth Rates and Allometric Relationships
}

\author{
Joseph M. Gray \\ Thesis submitted \\ to the Davis College of Agriculture, Natural Resources, and Design \\ at West Virginia University
}

In partial fulfillment of the requirements for the degree of

Master of Science in Forestry

Jamie Schuler, Ph.D., Chair

Melissa Thomas-Van Gundy, Ph.D.

Sophan Chhin, Ph.D.

Department of Forestry and Natural Resources

Morgantown, West Virginia

2020

Keywords: red spruce, reference curves, allometric relationships, understory

Copywrite 2020 Joseph M. Gray 


\section{ABSTRACT \\ Central Appalachian Understory Red Spruce (Picea rubens Sarg.) Growth Rates and Allometric Relationships \\ Joseph Gray}

Red spruce (Picea rubens) was a prized timber species in West Virginia during the era of resource exploitation in the late 1800s and early 1900s. Consequently, Central Appalachian red spruce has faced large reductions in range and changes in stand composition. This region is relatively underrepresented in literature partially due to these constrictions. Investigating how stem growth occurs in young individuals can fill in some of our gaps in understanding the species and aid in restoration efforts. We sampled an array of high elevation sites on federal and state lands in West Virginia to analyze understory spruce growth and allometric relationships. We compared these relationships to those found in other regions in the range of red spruce. Stem analysis was carried out on understory trees. Results were applied to build reference curves to model growth percentiles for the young trees. Growth rates tend to peak between 10 and 30 years of age. Heights range from $0.95 \mathrm{~m}$ to $6.85 \mathrm{~m}$ after 50 years. Results allow for comparison of growth rates to the cohort of understory red spruce regionally. Nonlinear analysis was carried out on allometric measures on the same cohort of red spruce. Diameter at breast height was found to be a somewhat reliable predictor of total height as well as crown width. Total height was less reliable when predicting crown width. None of the three measures were found to be reliable for predicting tree age as may be expected with a shade tolerant species. 


\section{ACKNOWLEDGEMENTS}

This study was made possible thanks to my advisor, Dr. Jamie Schuler. Thank you for helping me work through this project from the ideas up front to carrying out field work and analyses. Working with you over the last two years has been a rewarding experience. Thank you to Dr. Melissa Thomas-Van Gundy for guidance over the past two years while serving as my committee member and a contact with the Forest Service. Thank you to Dr. Sophan Chhin for allowing me to use your lab space and equipment in addition to the hours spent training me in dendrochronology methods.

Thank you to Dr. John Brown for allowing me to join you and your crew in field work and sharing your study sites, insight, and living quarters with me. Thank you to Eric Yetter for sharing your knowledge of red spruce and application of dendrochronology methods. Thank you to John Holden and Cameron Massey for helping me obtain and prepare cross-sections for analysis. Thank you to John Howell for setting me up with space and equipment to carry out sanding. Thank you to Dr. Ida Holaskova and Matthew Walker for helping me work through ideas and analyze my data. Once again thank you to Dr. Brown, Dr. Chhin, and Eric Yetter for sharing a subset of your data with me.

Funding was provided by the USDA Forest Service. Permission to conduct this study was obtained from the USDA Forest Service and the West Virginia Division of Forestry at Kumbrabow State Forest. It was an honor to work on the public lands in West Virginia on research that is so centric to this region.

Thank you to my professors at both the undergraduate and graduate levels for igniting my interest in forestry and science. You are great educators and even better people. Finally, thank you to my family and friends that have supported me through my time in school, especially my mother Lois and my good friends Brett and Emily. 


\section{TABLE OF CONTENTS}

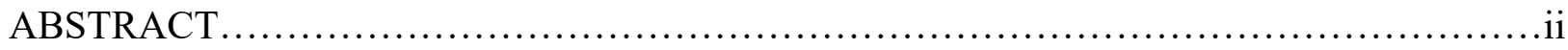

ACKNOWLEDGEMENTS...............................................................

LIST OF TABLES FIGURES AND APPENDICES .....................................vi

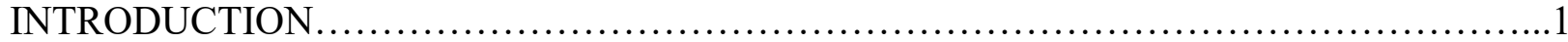

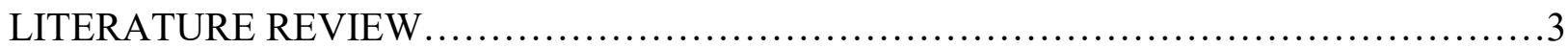

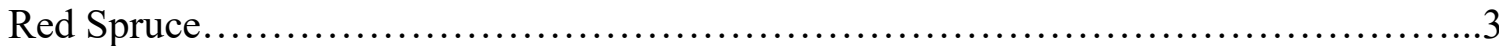

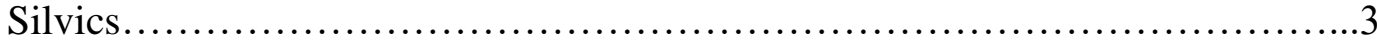

Red Spruce Range................................................... 4

Red Spruce in the Central Appalachians......................................5

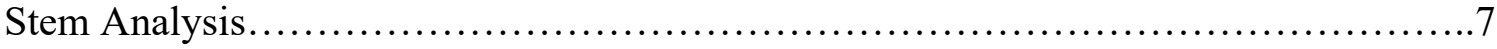

History of Stem Analysis..............................................

Site Index Using Stem Analysis..........................................

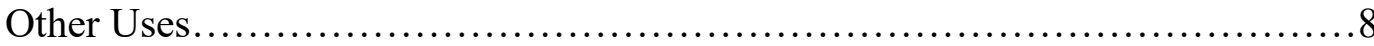

Reference Curves................................................................. 8

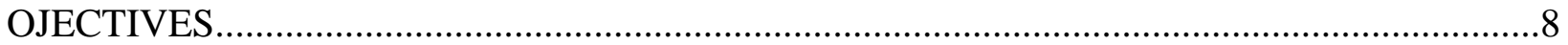

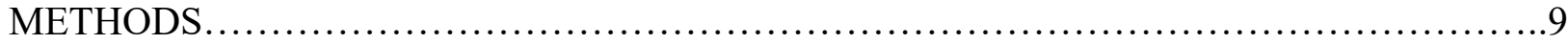

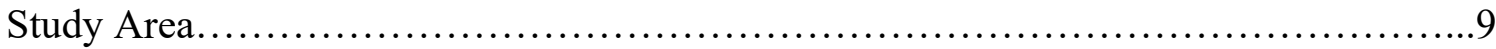

Sampling Techniques..........................................................

Plot Selection................................................................

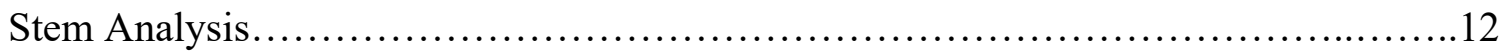

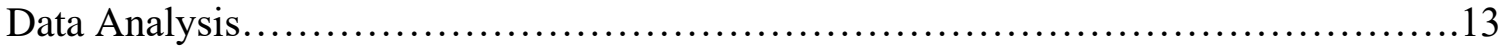

Reference Curves.........................................................

Analysis of Allometric Relationships......................................13

Suppression and Releases................................................ 13

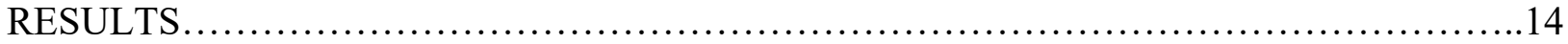

Characteristics of the Dataset.....................................................

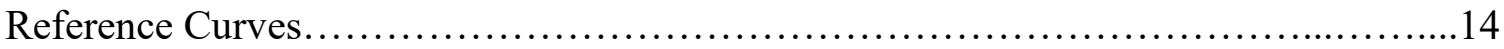




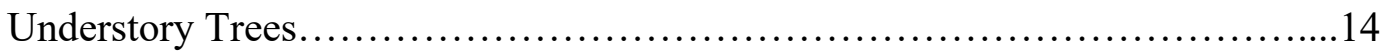

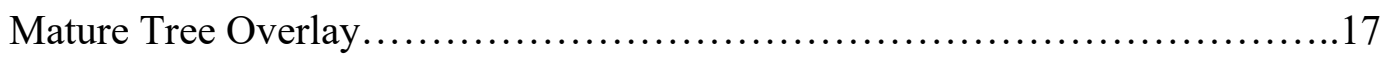

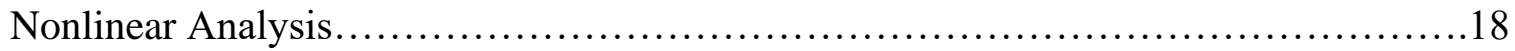

Allometric Relationships................................................................................19

Diameter at Breast Height Predicting Height..............................................19

Diameter at Breast Height Predicting Crown Width.................................20

Height Predicting Crown Width................................................................22

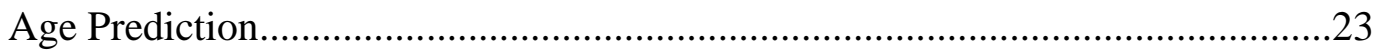

Diameter at Breast Height Predicting Age.................................................23

Height Predicting Age ..............................................................................25

Crown Width Predicting Age...............................................................26

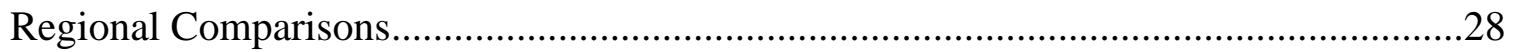

Diameter at Breast Height Predicting Height........................................................28

Diameter at Breast Height Predicting Crown Width..............................................29

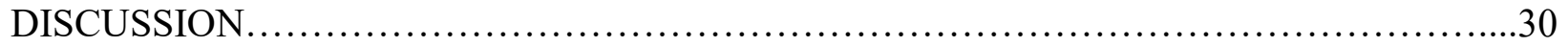

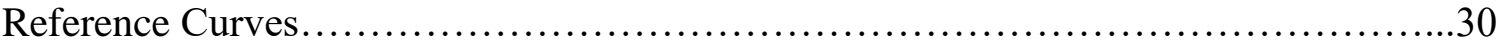

Understory Height Classes...............................................................................

Mature Tree Overlay.......................................................................................... 31

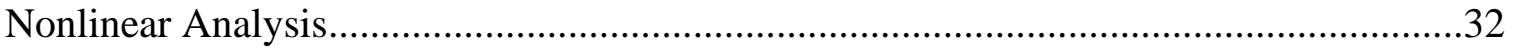

Allometric Relationships...................................................................................

Using Allometric Measurements to Predict Age..................................................32

Regional Comparisons..........................................................

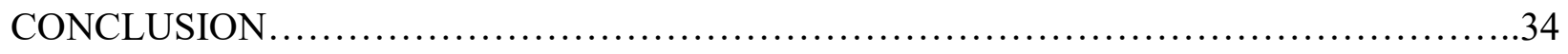

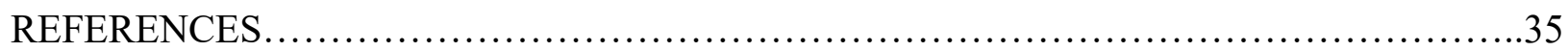

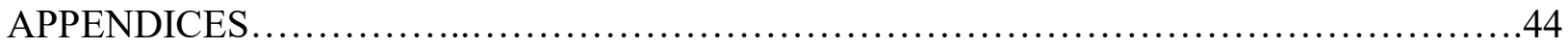




\section{LIST OF TABLES FIGURES AND APPENDICES}

Table 1: Table 1: Summary statistics for the three height classes of understory red spruce

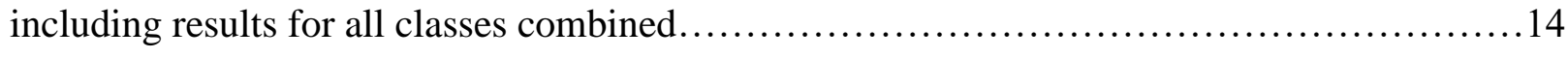

Table 2: Summary of the three best performing nonlinear models developed for the DBH predicting height relationship

Table 3: Model parameters for the three best performing models for the DBH predicting height relationship.

Table 4: Summary of the three best performing nonlinear models developed for the DBH predicting crown width relationship....

Table 5: Model parameters for the three best performing models for the DBH predicting crown width relationship.

Table 6: Summary of the three best performing nonlinear models developed for the height predicting crown width relationship.

Table 7: Model parameters for the three best performing models for the height predicting crown width relationship.

Table 8: Summary of the three best performing nonlinear models developed for the DBH predicting age relationship.

Table 9: Model parameters for the three best performing models for the DBH predicting age relationship.

Table 10: Summary of the three best performing nonlinear models developed for the height predicting age relationship....

Table 11: Model parameters for the three best performing models for the height predicting age relationship.

Table 12: Summary of the three best performing nonlinear models developed for the crown width predicting age relationship....

Table 13: Model parameters for the three best performing models for the crown width predicting age relationship.

Figure 1: Red Spruce plot locations in the Monongahela National Forest and Kumbrabow State Forest.

Figure 2: A six-by-six grid overlaid on Kumbrabow Site 1 used for subplot selection.... 
Figure 1: Cross-sections taken from destructively sampled red spruce $\ldots \ldots \ldots \ldots \ldots \ldots \ldots \ldots \ldots 12$

Figure 2: Height class centiles by age modelled in RefCurv (Winkler 2017).................16

Figure 5: Centiles for height growth by age for all understory red spruce modelled in RefCurv (Winkler et al. 2017) overlaid with early growth in 24 mature dominant and codominant red

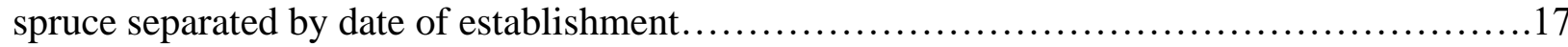

Figure 6: The top three nonlinear models produced using diameter at breast height to predict tree

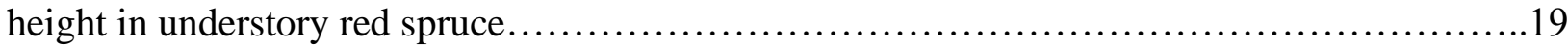

Figure 7: The top three nonlinear models produced using diameter at breast height to predict

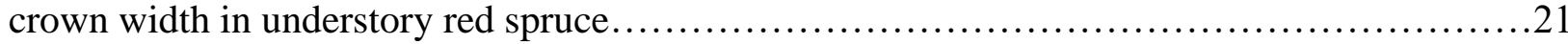

Figure 8: The top three nonlinear models produced using tree height to predict crown width in

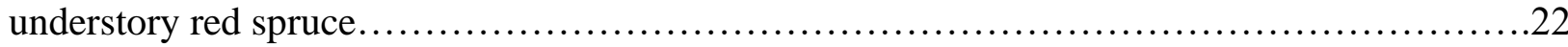

Figure 9: The top three nonlinear models produced using diameter at breast height to predict age

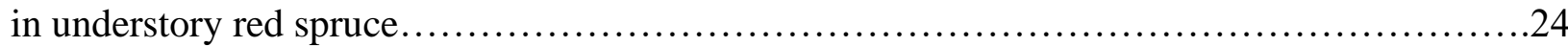

Figure 10: The top three nonlinear models produced using tree height to predict age in

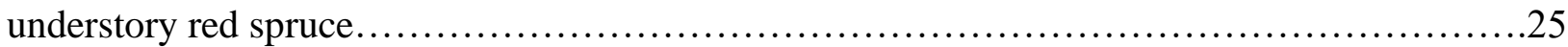

Figure 11: The top three nonlinear models produced using crown width to predict age in

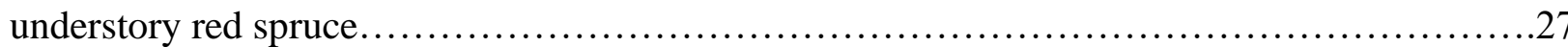

Figure 12: Comparison of diameter at breast predicting tree height using the Curtis-Arney equations (predicted) and the linear models developed for understory red spruce (actual).......28

Figure 13: Comparison of diameter at breast height predicting crown width using the equation developed by Bechtold (2003) and a matching power model developed using understory red

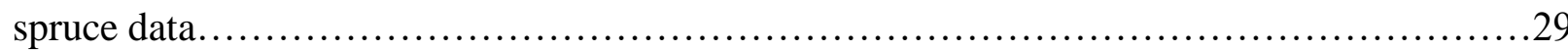

Appendix 1: The lambda, sigma, and mu values for the centiles modelled for height class one where " $\mathrm{x}$ " is age in years and " $\mathrm{P}$ " is percentile.

Appendix 2: The lambda, sigma, and mu values for the centiles modelled for height class two where " $\mathrm{x}$ " is age in years and " $\mathrm{P}$ " is percentile.

Appendix 3: The lambda, sigma, and mu values for the centiles modelled for height class three where " $\mathrm{x}$ " is age in years and " $\mathrm{P}$ " is percentile........................................ 51

Appendix 4: The lambda, sigma, and mu values for the centiles modelled for all height classes

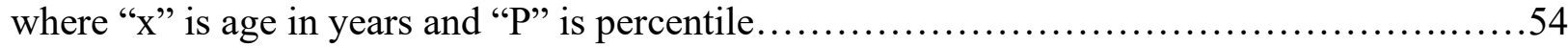

Appendix 5: Statistical output produced by RefCurve for the best fitting model for height class 1.

Appendix 6: Statistical output produced by RefCurve for the best fitting model for height class 2. 
Appendix 7: Statistical output produced by RefCurve for the best fitting model for height class 3.

Appendix 8: Statistical output produced by RefCurve for the best fitting model for all height

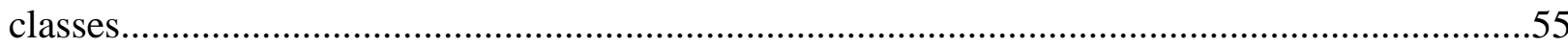




\section{INTRODUCTION}

Red spruce was a coveted timber species in the early days of European settlement in the Central Appalachian region. These forests were refugia on the highest peaks in the Alleghany Mountains after the last glaciation event. Estimates place pre-colonization forest extent between 200,000 and 600,000 hectares in West Virginia (Hopkins 1899; Stausbaugh and Core 1952). Exploitative logging practices in the 1800s and early 1900s extracted red spruce from the landscape at an unsustainable rate. Wildfire often followed resulting in the loss of some remnant trees and organic soil layers.

Current estimates place red spruce forests at 6-18\% of its former range in West Virginia (Griffith and Widmann 2003). The species no longer dominates much of its past domain. Pure stands of spruce are constricted further to high peaks and protected areas. Northern hardwoods now grow in conjunction with red spruce in many of the exploited stands of the past. Differences in soil, microclimate, competition, and disturbance now play a role in the development of young spruce. Other anthropogenic factors, some of which are more widely studied than others, also affect development. Climate change, forest pests, and acid rain have all played a role in a documented decline in the entirety of red spruce's range throughout much of the 1900s.

Red spruce habitat has begun to recover in the last 100 years. Accounts of the previous era mention impressive stands of pure red spruce climax forests notorious for their deep organic layer. Soil layers have developed to once again support regeneration in many stands. Spruce has encroached on hardwood ecotones (Rollins 2010, Nowacki et al. 2010, Mayfield and Hicks 2010). Deforested high elevation stands have regrown in some areas. There are increased efforts put forward to study and understand the species and its life history specific to the Central Appalachian region. Regeneration, disturbance, climate change, and many other factors all play a large role in better understanding this unique species (Adams et al. 1985; Schuler et al. 2002; Beane and Rentch 2015; Lutz 2018; Rentch 2007).

The importance of red spruce to West Virginia cannot be overstated. The species supports unique wildlife communities including the federally listed Cheat Mountain salamander and formerly listed Northern Virginia flying squirrel. Spruce forests cover some of the state's most scenic areas and tourist destinations. The species plays an important role in the identity and history of Central Appalachia as it supported the settlement of new towns and development of infrastructure. Red spruce may play an important role in mitigating climate change effects through carbon sequestration. Red spruce lines the headwaters of many of the region's most prominent watersheds. Timber value is generally restricted to niche markets in the region, but its value to the ecosystem is substantial.

In order to achieve a better understanding of red spruce and how it grows in the Central Appalachians, it is necessary to understand how it grows during seedling and sapling stages. 
Restoration efforts should have clear goals or parameters by which success is measured. Once we understand what growth rates have been successful in the past, we can apply that knowledge to present cohorts of young trees if conditions are believed to be similar. Red spruce can persist for decades in the understory of a stand. Knowing the development patterns of successful mature individuals may allow managers to understand which individuals have a reasonable chance at succeeding in the future.

This study addresses the following goals and objectives:

(1) To model the height growth patterns of understory red spruce growth.

(2) To compare the current height growth of understory red spruce to successful mature spruce when they themselves were growing in the understory.

(3) To gain a further understanding of allometric relationships in understory red spruce with a future goal of identifying characteristics of trees that have a chance to successfully ascend to the forest canopy.

These are some of the areas of research that may be necessary to understand how Central Appalachian red spruce will exist in years to come. This project can contribute to the conglomerate of studies carried out with the goal of preserving and increasing some of West Virginia's most celebrated ecosystems, red spruce forests. 


\section{LITERATURE REVIEW}

\section{Red Spruce}

\section{$\underline{\text { Silvics }}$}

Red spruce (Picea rubens) is a shade tolerant, monoecious medium-sized conifer. Flower buds emerge on the previous year's shoot growth and open in May. Cones develop from July until the following spring maturing in September and October. Cones are only fully open for a few days during which they are receptive to pollen (Youngblood and Safford 2008). Good seed years occur every 3 to 8 years with lighter crops common during interim years (Hart 1965). Seeds are primarily wind dispersed travelling as far as 300 feet (Walter 1967; Randall 1974). Seed drops in the fall and can germinate soon after but more often in the following spring and summer. In strong years 60 to 80 percent of seed is viable (Koristian 1937). Viability rarely extends beyond one year after seed fall due to drying (Frank 1970). Seed is commonly predated by small mammals (Blum 1990; Abbott and Hart 1960; Hart et al. 1968). Mineral soil that maintains moderate temperatures is a preferred medium due to moisture availability (Hart 1965). Other forms of reproduction outside of seed germination (e.g., vegetative reproduction) are rare (Gordon 1976).

Reproduction establishes well in shaded areas with as little as $10 \%$ direct sunlight although seedlings grow optimally at levels greater than 50\% once established and heights of 15 $\mathrm{cm}$ are reached (Frank and Bjorkbom 1973). Growth can be exceptionally slow until light is increased through disturbance. Regeneration is more common on cool and moist north and east facing slopes where exposure to sunlight is decreased (Baldwin 1933). Growth medium is a major determinant for seedling survival. Leaf litter moisture fluctuations may reduce survival compared to a bryophyte layer which provides adequate moisture and nutrients (Dibble 1999).

Saplings can vary greatly in age and are influenced heavily by direct sunlight. Trees can reach heights of 7 meters in 20 years if open growth is experienced (Hart 1965). Seed production can begin as early as 15 years of age but is more likely to occur in mature individuals (Frank and Bjorkbom 1973, Korstian, 1937). Trees can take longer than 100 years to reach biological maturity. Smaller crowns yield slower growth (Hart 1959, Hart 1965). Mature red spruce can reach heights up to 35 meters in the southern portions of its range but is restricted to a medium sized tree in the northeast reaching heights of 18-23 meters. (Burns and Honkala 1990). The species is long-lived with recorded individuals reaching 400 years of age (Hart 1965).

Red Spruce grows well in moist, cool environments. Sites experiencing wet growing seasons and cold winters create favorable conditions for the species (Saunders 1983). The species is shallow rooting making it susceptible to windthrow. Acidic soils between a $\mathrm{pH}$ of 4 and 6 are preferred and compounded by its own leaf litter (Frank and Bjorkbom 1973). Well and moderately-well drained inceptisols and spodosols are common soil orders that support red 
spruce (Jenkins 2002). Sandstone and shale are common parent materials in the Central Appalachians (Price 1968). Soils can be rocky depending on topography and location. Red spruce stands are commonly characterized by a deep humus layer with high moisture holding capacity (Frank and Bjorkbom 1973).

Due to its shallow rooted nature (Greenwood et al., 2008) leaving it susceptible to windthrow, small gap openings from single trees or small groups of trees serve as the main disturbance in red spruce stands (Eager and Adams 1992, Fraver and White 2005). Response to release can occur after many years of suppression (Burns and Honkala 1990). Multiple releases are often needed to allow ascension into the canopy (Wu et al. 1999, Rentch et al. 2010) and many understory trees have already undergone one or more releases (Rentch et al. 2007). Small gaps have shown greater success in implemented treatments (Dumais and Prevost, 2016). Shelterwood treatments and thinning from above are common treatments to mimic natural disturbance (Sendak et al. 2003, Rentch et al. 2007, Carter et al., 2017). Mean gap size in spruce and spruce-hardwood stands has been recorded from around 50 square meters in the Central Appalachians (Rentch et al. 2010; Lutz 2018) to 66 square meters in the Northeast (Fraver and White 2005).

Red spruce can grow in pure stands but commonly grows in association with a number of other tree species. It is considered shade-tolerant (Burns and Honkala 1990). The Society of American Foresters recognizes red spruce as a major component of Red Spruce-Yellow Birch, Red Spruce-Sugar Maple-Beech, Red Spruce-Balsam Fir, and Red Spruce-Fraser Fir forest types, although it grows in a number of other forest types as a lesser component. Associated species in West Virginia include eastern hemlock (Tsuga canadensis), yellow birch (Betula alleghaniensis), American beech (Fagus grandifolia), black cherry (Prunus serotina), red maple (Acer rubrum), and sugar maple (Acer saccharum) (Rentch et al. 2016). Associated fauna include the formerly federally listed Virginia northern flying squirrel and the federally threatened Cheat Mountain Salamander endemic to red spruce stands of West Virginia (Schuler et al. 2002).

\section{Red Spruce Range}

Red Spruce is endemic to the eastern United States and Canada. Its range is commonly split into three distinct regions: the northeast, the central Appalachians, and the southern Appalachians. The northeast region is the most contiguous and encompasses most of New England and stretches into Canada as far north as the Maritime Provinces, west into portions of Ontario, and south into pockets of Pennsylvania. The Central Appalachian populations become more isolated and restricted to high elevations primarily in West Virginia but also Pennsylvania, western Maryland, and Northern Virginia. The southern Appalachian population is constricted to high elevations in western North Carolina, eastern Tennessee, and southwest Virginia (Burns and Honkala 1990). The Central Appalachian population shows several distinctions from the other regions. Red spruce stands tend to occur at or above 1067 meters (Hicks and Mudrick 1994) which is a lower elevation compared to the Southern Appalachians. Spruce-fir stands that can be 
found in the Northeast and Southern Appalachians are uncommon in the Central Appalachians (Stephenson and Clovis 1983). Spruce budworm and spruce bark beetles are notably absent from the region.

\section{Red Spruce in the Central Appalachians}

Pollen records indicate spruce forests were present in the Central Appalachians 12,000 years ago following the northern retreat of the Wisconsin glaciation and tundra-like conditions in the region. As Tsuga and several hardwood genera began to appear around 10,000 years ago, Picea dropped from pollen records indicating a movement to higher elevations as climate warmed. Picea once again appeared in the record less than 5,000 years ago as Tsuga notably became absent likely reducing interspecies competition (Watts 1979, Rollins 2010). The range of red spruce in the region has been relatively consistent for 6,000 years (Jacobson et al. 1987) or has possibly increased due to cooler and wetter conditions (Delcourt and Delcourt 1984).

Documentation of the region's forests are somewhat absent during early European settlement. Journal entries and logging records can be used to gain some understanding of composition and conditions; although their accuracy cannot be confirmed. In fact, some errors can be used to highlight just how unreliable observations of the period were. Misidentification and exaggeration are said to run rampant through these accounts (Bailey and Ware 1990, Clarkson 1964). Loggers of the era were unable to provide ecological descriptions of spruce forests, although size of mature trees were recorded as large as two meters in diameter (Clarkson 1964, Allard and Leonard 1952). Virgin spruce stands in high elevations were likely pure stands with a simple understory composition of shade tolerant tree and shrub species (Allard and Leonard 1952). Lower elevations yielded mixed composition containing black cherry, American beech, sugar maple, eastern hemlock, yellow birch, and balsam fir (Abies balsamea) as well as pin cherry (Prunus pensylvanica) in times following disturbance (Allard and Leonard 1952).

European expansion into West Virginia in the late 1800s decimated many areas of the Central Appalachians previously deemed inaccessible. Estimates approximate between 200,000 hectares of red spruce forest prior to this period up to 600,000 hectares including mixed stands (Hopkins 1899; Stausbaugh and Core 1952). The use of steam powered railroads and logging equipment increased productivity and transport for logging operations (Clarkson 1964). Red spruce was a favored species. Widespread clearcuts followed in order to extract timber and clear land for agriculture. Wildfire was common after clearcutting resulting in the destruction of much of the seed bed and seedlings in stands previously dominated by spruce as well as organic soil beneath (Lewis 1998). Subsequent conditions favored the establishment of hardwood species (Thomas-Van Gundy and Sturtevant, 2014). Open canopy conditions allowed faster growing understory species to overtake any remaining spruce regeneration. The resulting hardwood overstory produced unfavorable conditions for spruce. A more open canopy retained less moisture in months of summer drought and made seedlings vulnerable to winter conditions in areas where dense spruce canopy had protected young trees (Adams and Stephenson 1989). 
Recent reports estimate 12,000 hectares of red spruce forest remaining in West Virginia, somewhere around 6-18\% of the original area (Griffith and Widmann 2003). A recent report shows 62,000 hectares available for management of red spruce and spruce-hardwood communities, although some sites are more suited more northern hardwoods (Moore 2011).

Public land has become a stronghold for the remaining red spruce in West Virginia. Established in 1920, the Monongahela National Forest has acquired additional units of land throughout the twentieth century to reach its current size. Its highest elevations encompass the majority of the range of red spruce forest in West Virginia (Griffith and Widemann 2003). These sites often have a history of logging and burning which interrupted natural disturbance regimes of the region (Thomas-Van Gundy and Strager 2012). Understory ages vary within most stands indicating continuous establishment. Site index varies by elevation and soil types as noted by Flegal (1999) in surveys of Pocahontas County. Stand age is variable by location with many originating between 1890 and 1930 from clear-cut harvests and some containing residuals from the mid-1800's (Rentch et al. 2016). Kumbrabow State Forest atop Rich Mountain in Randolph County, West Virginia is another example of historical decline and present-day management of red spruce. Established in 1934 after enduring decades of logging and wildfire, the forest represents similar conditions to much of the region's red spruce stands. Prior to its acquisition by the state in 1934, the Midland Corporation utilized the area for timber harvest. At least four major sawmills sourced timber from the forest while operating a spur railroad line for removal. Fires followed these harvests. Additional harvests occurred throughout the 1950's and 1960's prior to establishing silvicultural prescriptions in 1975. Seven harvests occurred between 1977 and 2001 averaging 80 hectares in size. Much of the current management focuses on promoting shade-tolerant species including red spruce as the current stands display an even-aged distribution dominated by hardwoods (WVDOF 2002).

A more recent decline in growth in the Central Appalachians has been noted although the cause is not certain. Adams et al. (1985) and Schuler et al. (2002) both noted a decline in growth for red spruce in the region with the latter finding the period lasting around 60 years beginning in the 1930s. Mielke et al. (1986) found concerning rates of mortality in West Virginia spruce stands during the same period. Although several anthropogenic stressors have been discussed, climate change has become a leading concern for red spruce in the region (Johnson et al 1988, Hamburg and Cogbill 1988, Beane and Rentch 2015, Mathias and Thomas 2018). Current models indicate a loss of over half of the region's suitable red spruce habitat within the next 5 years and potentially all suitable habitat by 2080 (Beane and Rentch 2015) likely leaving remnant stands at only the highest elevations. Even so, some communities dominated by red spruce have undergone recent expansion in ecological status and have extended into the ecotone while increasing in number of stems (Rollins 2010, Nowacki et al. 2010, Mayfield and Hicks 2010) showing a level of resilience in the population.

Based on historic records and modern studies, the composition of interspecies competition is not extremely different after periods of logging and decline. Allard and Leonard 
(1952) noted two types of red spruce forests; high elevation stands containing pure spruce and lower elevations where spruce began to mix with northern hardwood species and eastern hemlock. Today a similar distinction can be found. Unfortunately, it is unknown what portion of the canopy spruce filled and at what elevation these mixed stands existed in the past to compare to today's structure. Common associates between the two eras include eastern hemlock, American beech, yellow birch, red maple and black cherry (Lutz 2018, Pauley 1989, Adams and Stephenson 1989, Allard and Leonard 1952, Hopkins 1899).

\section{Stem Analysis}

The History of Stem Analysis

Stem analysis is a method used to examine tree cores or cross-sections to learn about how it grew throughout its life. The technique utilizes growth rings to obtain ages at different heights of the tree. Records of stem analysis in the United States date back to the late 1800s (Mlodiansky 1898). The process can reconstruct both radial and height growth throughout the life of a tree by measuring diameter and height of cross-sections or cores extracted incrementally along the bole. Early adopters used tree height and diameter measurements to determine volume and height development. A practical issue arises when estimating height at an age between sampled crosssections, even more so when several age transitions occur. Multiple methods to correct for this, each with different assumptions, have been reported in the literature. Some were found more accurate than others. For example, Dyer and Bailey (1987) found Carmean's (1972) method, which assumes height growth between cross-sections is constant and that the cross-section sampled occurs in the middle of the year's growth, as the most accurate method when tested against both older (Mlondiansky 1898; Graves 1906) and modern methods (Lenhart 1972; Newberry 1978). Kariuki (2002) found that a tree annual radial growth method can outperform other methods, assuming annual radial growth percentage is associated with annual height growth percentage, at the cost of more labor and equipment for analysis. Even so, Carmean (1972) and Lenhart's (1972) methods are still deemed acceptable.

\section{$\underline{\text { Site Index Using Stem Analysis }}$}

Currently, stem analysis is a common method employed for developing site index curves, although estimates are less accurate than using data from permanent or temporary sample plots (Allen and Burkhart 2015). Site index calculated from stem analysis will often underestimate the height of young trees yielding an overestimation of future growth in a stand due to the assumption that growth is free of suppression at all ages (Magnussen and Penner 1996). As a shade tolerant species with the ability to persist under suppression for many years, red spruce is a poor candidate for the traditional method of calculating site index. Griffin et al. (1970) used polymorphic site index curves to account for this in even-aged stands. Seymour and Favian (2001) found by substituting areas of suppression with an adjusted age, which is the number of 
years resulting in equal radial growth under non-suppressed conditions, site index calculations in shade tolerant species become more accurate. Otherwise studies involving shade tolerant species' site index will be limited to even-aged pure stands. Earlier methods simply substituted diameter for age on the site index curve (McLintock and Bickford 1957).

\section{$\underline{\text { Other Uses }}$}

Stem analysis is not limited to site index studies. It is a method that can help answer applied and practical questions in the field. Zenner (2012) used the method to answer if dominant oaks were ever shorter than direct competitors. LeBlanc (1990) notes that detailed stem analysis is costly, but indices can be derived to model whole stem growth in trees where a single core is taken at breast height. Stem analysis has yielded tree-specific stem profile models (Yang 2009) as well as taper equations from both destructive (Larsen 2017) and standing tree analysis (Westfall and Scott 2010). Stem analysis provides detailed data about tree growth resulting in a variety of equations and models at the cost of the sampled resource. Alternatively, labor is saved overall by reducing entries into a plot to carry out many measurements over the lifetime of a tree.

\section{Reference Curves}

Reference curves are frequently used in the medical field to assess growth and development of a cohort. Centiles can be modelled from the distribution of the measurement of interest and plotted against age. An individual can then be assessed using the distribution's centiles to quantitively compare them to their peers (Ulijaszek et al. 1998). The lambda-musigma (LMS) method can be used to normalize a data set prior to plotting reference curves (Cole 1990). Similarly reference curves have been applied to other cohorts outside of the medical field. A number of studies have developed reference curves for the body mass index (BMI) of wildlife species (Nesbitt 2008; Curry 2020; Mech 2006). Vickers et al. (2017) used reference curves to assess tree performance in young oak stands. To date these methods have yet to be applied to shade-tolerant species including red spruce. Managers are interested how the development of seedlings occur in their stands as well as how it compares to other stems in the region. Reference curves may give us the opportunity to answers these questions.

\section{OBJECTIVES}

This study modelled the understory development of red spruce in the Central Appalachians, specifically West Virginia. The primary objective was to identify the variation in understory individuals and quantify the rates at which they grew with future objectives including developing applied management strategies using this information. Specific goals included: 1) to model the height growth patterns of understory red spruce growth;2) to compare the current height growth of understory red spruce to successful mature spruce when they themselves were growing in the understory; 3) to gain a further understanding of allometric relationships in 
understory red spruce with a future goal of identifying characteristics of trees that have a chance to successfully ascend to the forest canopy.

\section{METHODS}

\section{Study Area}

Sampling was distributed across three counties in eastern West Virginia. Twenty plots containing red spruce were located within Tucker, Randolph, and Pocahontas Counties on the Monongahela National Forest, and two additional plots located on Kumbrabow State Forest in Randolph County (Figure 1). The red spruce forests sampled were near the highest points of the region between $1000 \mathrm{~m}$ and $1482 \mathrm{~m}$ in elevation.

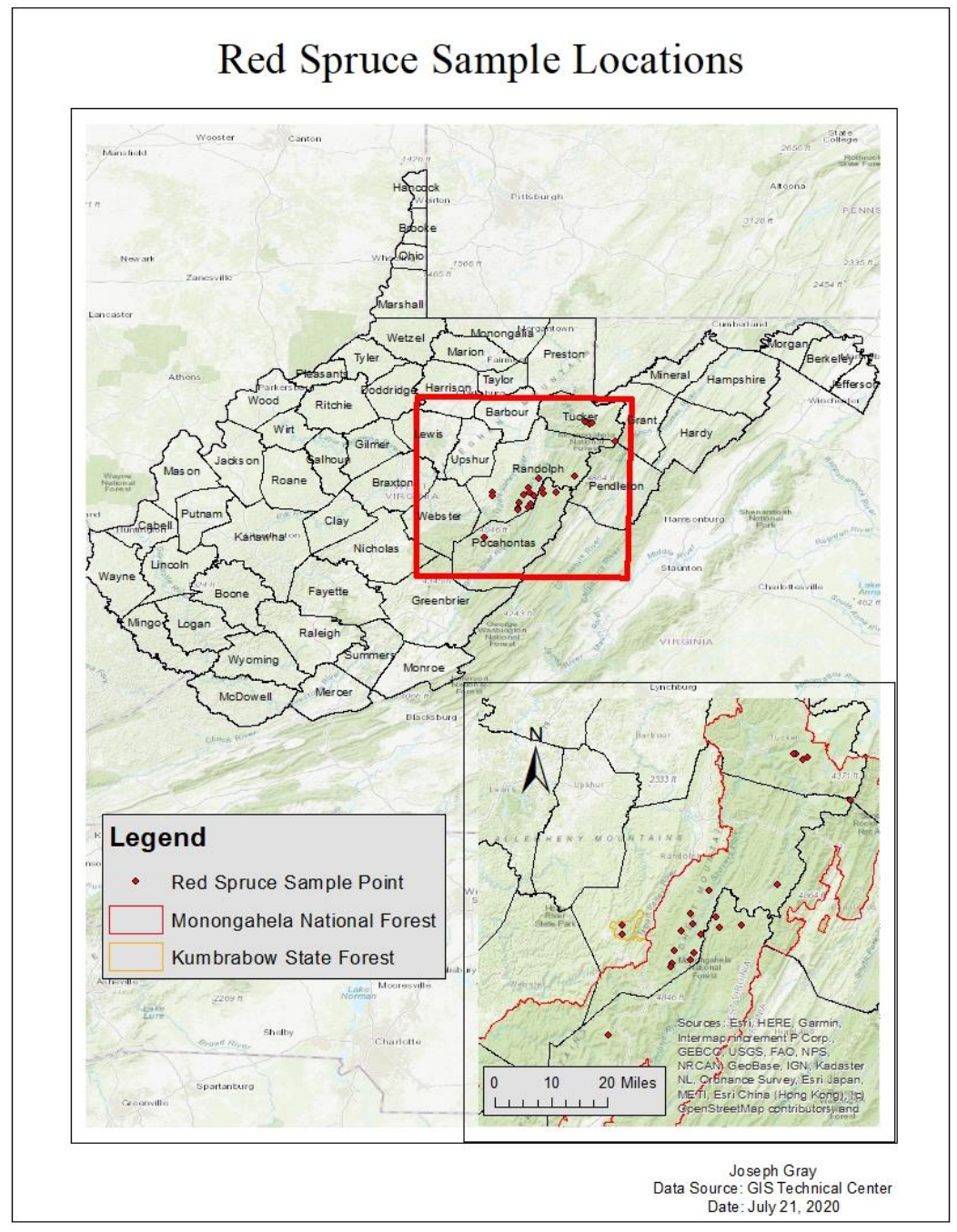

Figure 3: Red Spruce plot locations in the Monongahela National Forest and Kumbrabow State Forest. 
Sampling locations were strongly dominated by red spruce but also contained hardwood and other conifer species. Common associates included eastern hemlock, yellow birch, American beech, black cherry, Fraser magnolia (Magnolia fraseri), red maple, and sugar maple. The historical landuse and anthropogenic disturbances of these areas are typical of the region. These areas were clear-cut during the late 1800s through the early 1900s (Rentch et al. 2016). Fires often followed the harvesting, which interrupted the natural disturbance regimes of the region (Thomas-Van Gundy et al. 2007). Some of these stands now contain a few individuals that originated from the mid-1800s, but the majority of the understory trees have ages that are quite varied, indicating continuous establishment.

Site index ranges from 42 to 65 feet at a base age of 50 depending on elevation and soil type as noted by Flegal in surveys of Pocahontas County (1999). The soils associated with red spruce and northern hardwood dominated stands contain well and moderately well drained inceptisols and spodosols (Jenkins 2002). Parent materials are often Pennsylvanian subperiod sandstone and shale (Price 1968). Soils are rocky and acidic partially attributed to red spruce organic matter.

Regionally, annual precipitation averages $156 \mathrm{~cm}$ (Rentch et al. 2016, NCDC 2020), while some areas receive as much as $180 \mathrm{~cm}$. Precipitation near the sample plots ranged 122 to $168 \mathrm{~cm}$ annually. Average daily temperatures are highest in July, ranging between $16.1^{\circ} \mathrm{C}$ and $17.7^{\circ} \mathrm{C}$, and lowest in January between $-3.1^{\circ} \mathrm{C}$ and $-4.8^{\circ} \mathrm{C}$ (PRISM, Oregon State University).

\section{Sampling Techniques}

\section{$\underline{\text { Plot Selection }}$}

Using the West Virginia GIS Technical Center's data (2013) for red spruce cover in West Virginia, the potential range of the species within the state was superimposed over the Monongahela National Forest boundary in ArcMap 10.6. One hundred fifty random points (plots) were generated for consideration. From these points, 100 sites containing red spruce overstory trees were sampled for a companion site index project (Yetter 2020). A subset containing 20 sites was selected for this study.

Kumbrabow State Forest plots were selected from two sites known to contain a dominant red spruce overstory component. Two mature dominant or codominant red spruce were sampled at each plot. Rather than cutting a mature tree for destructive sampling, recent windthrown trees were selected for stem analysis. The stands are undisturbed in recent years making the pattern of windthrow natural if not somewhat random, although the degree of randomness is related to site factors including slope and soil depth, influencing which trees are more likely to succumb (Eager and Adams 1992). 
At each sample point location, the first mature red spruce encountered moving clockwise from a random bearing from plot center was felled, except at the Kumbrabow sites as discussed. Once felled, disks were removed from the stem at specific locations and used to reconstruction growth patterns. The specific locations and processing techniques were the same as for seedling and sapling trees described below.

The understory seedling and sapling layer was sampled at each location. For each site, 36 potential sampling locations were delineated in ArcMap 10.6 (Figure 3). Four locations were randomly selected. Due to different stand sizes, the distance between subplots differed among sites, ranging from 25 and $90 \mathrm{~m}$.

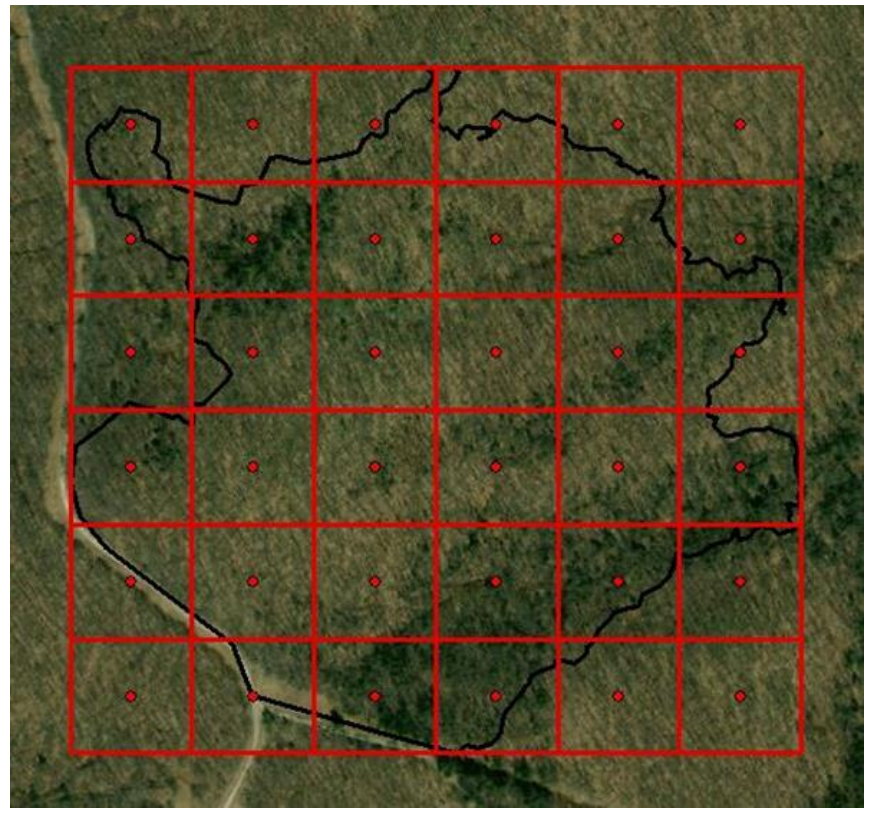

Figure 4: A six-by-six grid overlaid on Kumbrabow Site 1 used for subplot selection.

Twelve understory red spruce were sampled at each site ( 3 per subplot). At each subplot, an individual red spruce was harvested for each of three height classes: $0.1 \mathrm{~m}$ to $2.6 \mathrm{~m}, 2.6 \mathrm{~m}$ to $5.1 \mathrm{~m}$, and 5.1 to $7.6 \mathrm{~m}$. The closest tree in each height class was sampled at each of the four designated subplots in the stand. A total of 288 understory red spruce trees were destructively sampled.

Cross-sectional disks were cut at $0 \mathrm{~m}$ or as close to the ground as possible, $0.3 \mathrm{~m}, 0.6 \mathrm{~m}$, $0.9 \mathrm{~m}, 1.37 \mathrm{~m}$ (breast height), $2.37 \mathrm{~m}, 3.37 \mathrm{~m}, 5.37 \mathrm{~m}$, and $7.37 \mathrm{~m}$ (Figure 3). Most sampled trees did not include all possible cross-sections since their total height was below the height of the cross-sections. Total height, height to live crown, diameter at breast height, and crown diameter major and minor axis were all recorded. Additionally, aspect, percent slope, and presence of a gap or overtopping species were recorded. 


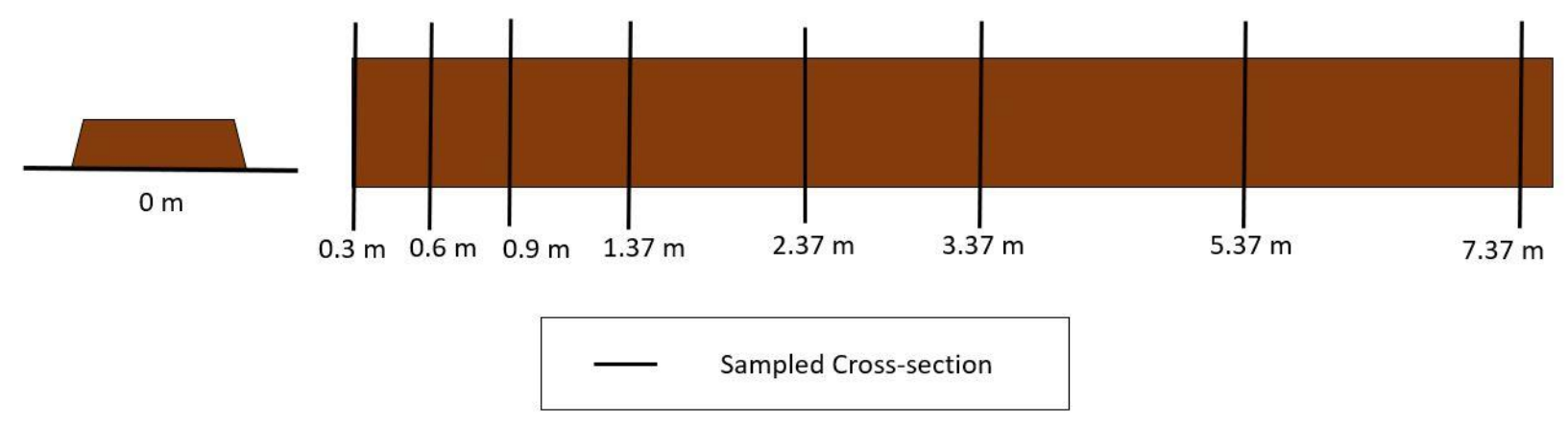

Figure 5: Cross-sections taken from destructively sampled red spruce.

\section{Stem Analysis}

Cross-sections were air-dried for several weeks then sanded using progressively finer sandpaper finishing with 600 to 800 grit. Disks were scanned at 2400 dpi (Epson Expression 12000XL and Epson Perfection V600) and uploaded into CooRecorder 9.01 software (Cybis Elektronik \& Data AB; Saltsjobaden, Sweden) prior to visually cross dating using the list method described by Yamaguchi (1991). Files were then assessed through COFECHA (Version 6.06P) separated by plot to statistically determine cross-dating accuracy. Flags or potential mistakes were viewed and corrected when appropriate until a minimum satisfactory master correlation value of 0.35 was reached. Overstory samples could not be statistically cross-dated due to small sample size. As an alternative, two random transects were counted and reviewed for discrepancies (Stokes and Smiley 1968). A small number of samples were removed prior to analysis due to the presence of injury, rot, or severe reaction wood that influenced accurate ring identification. Five of nine cross-sections taken from mature spruce in the Monongahela National Forest were sanded and aged for the companion site index project and shared with this study (Brown et al. unpublished).

The Carmean method (1972) was used to calculate height at ages between cross-sections. This method assumes annual height growth between cross-sections is constant and that the crosssection was sampled in the middle of the year's height growth. From these data, growth rates between heights were determined and used to build growth curves for individual trees using the equation:

$$
\begin{aligned}
& H_{i j}=h_{i}+\left(h_{i+1}-h_{i}\right) /\left[2\left(r_{i}-r_{i+1}\right)\right]+(j-1)\left(h_{i+1}-h_{i}\right) /\left(r_{i}-r_{i+1}\right) \\
& \text { Where: } \\
& \qquad \begin{array}{ll}
H_{i j} & =\text { estimated tree height at age of the } j \text { th inner ring } \\
h_{i} & =\text { height at } i \text { th crosscut } \\
r_{i} & =\text { rings at } i \text { th crosscut } \\
j & =\text { age transition between cross-sections }
\end{array}
\end{aligned}
$$




\section{Data Analysis}

\section{$\underline{\text { Reference Curves }}$}

Reference curves were used to develop separate growth standards for height by age among the three height classes for the understory red spruce and a composite set of curves for all height classes. The RefCurv software package (Winkler et al. 2019) was used to carry out the lambda-mu-sigma (LMS) method. This method utilizes the Box-Cox Cole Green distribution to penalize splines of the three parameters for which it is named in order to normalize their distributions throughout the range of ages present. A degree of freedom is set for each lambda, $\mathrm{mu}$, and sigma using Bayesian information criterion (BIC) prior to using the Rigby and Stasinapoulos algorithm (Stasinopoulos et al. 2017) to fit the curves in R (R Core Team; Vienna, Austria). Higher degrees of freedom provide a more flexible curve to fit the data. Simple models will have lower degrees of freedom. Although this procedure is fairly standard in the medical field, it is less prominent in the natural sciences. Vickers et al. (2017) carried out similar work to model young stands in the Missouri Ozarks.

Prior to inputting data into the RefCurv program an outlier analysis was carried out on the age distribution of all understory trees and on each individual height class. Data points beyond three standard deviations from the mean, less than $1 \%$ of all points, were removed to avoid individual trees heavily influencing portions of the curves. Individual mature tree growth histories were then overlaid to compare growth to the centiles for each understory height class. Analysis of Allometric Relationships

Nonlinear analysis was used to model allometric relationships in JMP 14 (SAS Institute Inc.; Cary, NC). Diameter at breast height was used to predict tree height and crown width, while height was used to predict crown width. Deviations in polynomial, sigmoid, and exponential fits were compared. Akaike information criterion (AIC) was used to determine the best model for each relationship. Visual confirmation was necessary to check if the best model in terms of AIC score did not overpredict changes where data were absent. Equivalence analysis was used to assess significant differences between height classes. Simple regression was attempted prior to nonlinear analysis but the assumptions of normality of errors and homoscedasticity of errors were not met. Data transformations attempted failed to achieve normality as well. Similar nonlinear analysis was carried out to determine if any of the three measures (DBH, height, age) could reliably predict tree age.

Suppression and Releases

Number of releases were calculated using percent growth change in the second crosssection $(0.3 \mathrm{~m})$ of each sample as described by Rentch et al. (2007). Radial means were calculated in rolling 10-year averages. A 100\% increase in radial increment indicated a release in understory samples (Lorimer and Frelich 1989). Periods of suppression were then identified as time between release events. 


\section{RESULTS}

\section{Characteristics of the dataset}

A total of 252 understory red spruce trees were used in final analyses. Understory red spruce were growing on sites with average slopes of 9.9 percent, while the most common aspect was north facing. The most common overtopping species was red spruce (39\%), followed by red maple $(21 \%)$ and yellow birch (15\%). At the time of sampling $7.5 \%$ of the trees were located within a gap with an average area of $41 \mathrm{~m}^{2}$. Most understory trees had never experienced a release. Table 1 highlights allometric differences between samples of different height classes. As expected, the taller samples were on average older than those in the shorter classes but the range in mean age was only 11 years. Every measurement taken produced higher means for the larger height class. Mean annual growth in the largest individuals was more than triple that of the smallest class.

Table 1: Summary statistics for the three height classes of understory red spruce including results for all classes combined

\begin{tabular}{cccccccc}
\hline Height Class & $\mathbf{N}$ & $\begin{array}{c}\text { Mean } \\
\text { Height }(\mathbf{m})\end{array}$ & $\begin{array}{c}\text { Mean Live Crown } \\
\text { Height }(\mathbf{m})\end{array}$ & $\begin{array}{c}\text { Mean } \\
\text { DBH }(\mathbf{c m})\end{array}$ & $\begin{array}{c}\text { Mean Crown } \\
\text { Width }(\mathbf{m})\end{array}$ & $\begin{array}{c}\text { Mean Age } \\
(\text { years })\end{array}$ & $\begin{array}{c}\text { Annual Height } \\
\text { Growth }(\mathbf{m})\end{array}$ \\
\hline $\mathbf{1}(\mathbf{0 . 1 - 2 . 6} \mathbf{m})$ & 83 & 1.22 & 0.53 & 1.17 & 0.68 & 29.8 & 0.04 \\
$\mathbf{2}(\mathbf{2 . 6 - 5 . 1} \mathbf{m})$ & 85 & 3.47 & 1.50 & 3.84 & 1.27 & 42.15 & 0.09 \\
$\mathbf{3}(\mathbf{5 . 1 - 7 . 6} \mathbf{m})$ & 84 & 5.87 & 2.74 & 7.08 & 1.83 & 50.71 & 0.13 \\
\hline All Classes & 252 & 3.53 & 1.59 & 4.86 & 1.26 & 40.94 & 0.09 \\
\hline
\end{tabular}

\section{Reference Curves}

$\underline{\text { Understory Trees }}$

Reference curves built for height class 1 (Figure 4) show almost immediate differentiation in the $90^{\text {th }}$ and $97^{\text {th }}$ percentiles compared to lower centiles where differences become more apparent around 20 years. Modelling growth to 50 years of age showed heights spanning from $0.67 \mathrm{~m}$ ( $3^{\text {rd }}$ percentile) to $2.48 \mathrm{~m}$ ( $97^{\text {th }}$ percentile). Growth appears to level off with no indication of an age where widespread release occurs for any of the centiles. The LMS degrees of freedom producing the best Bayesian Information Criterion (BIC) score (-651.9) were 0,3 , and 0 respectively. The fit of the model was significant to a 0.0001 level (Appendix 5).

Reference curves built for height class 2 (Figure 4) display more immediate differences between several of the upper centiles $\left(75^{\text {th }}, 90^{\text {th }}\right.$, and $97^{\text {th }}$ percentiles $)$. All centiles increase in growth rate between ages 10 and 20 years. This increase is more pronounced in the upper centiles. Growth begins leveling off after 20 years of age. At 50 years of age, the model ranges in 
heights between $1.28 \mathrm{~m}$ ( $3^{\text {rd }}$ percentile) and $4.52 \mathrm{~m}\left(97^{\text {th }}\right.$ percentile). The LMS degrees of freedom producing the best BIC score (4628.8) were 0,5 , and 4 respectively. The fit of the model was significant to a 0.0001 level (Appendix 6).

Reference curves built for height class 3 produced the widest range of results. Differences in height and growth rates are apparent for most centiles after 10 years. Growth rates were highest between 10 and 30 years of age for the upper centiles $\left(75^{\text {th }}, 90^{\text {th }}\right.$, and $97^{\text {th }}$ percentiles). Growth rate remained fairly constant for the $50^{\text {th }}$ percentile. Lower centiles $\left(3^{\text {rd }}, 10^{\text {th }}\right.$, and $25^{\text {th }}$ percentiles) display constant growth until age 30 where growth rate begins to increase. At 50 years the model ranges in heights from $1.58 \mathrm{~m}$ ( $3^{\text {rd }}$ percentile) to $7.25 \mathrm{~m}\left(97^{\text {th }}\right.$ percentile). The LMS degrees of freedom producing the best BIC score (10075.6) were 0,0 , and 3 respectively. The fit of the model was significant to a 0.0001 level (Appendix 7).

All height classes were compiled to model a comprehensive set of reference curves for understory red spruce. The upper centiles $\left(90^{\text {th }}\right.$ and $97^{\text {th }}$ percentiles) showed immediate differentiation in growth rates from the lower centiles. The $50^{\text {th }}$ and $75^{\text {th }}$ percentiles showed faster growth compared to the lowest centiles by year 10 . The lowest centiles $\left(3^{\text {rd }}, 10^{\text {th }}\right.$, and $25^{\text {th }}$ percentiles) were similar in growth until year 20. Growth rates were largest between year 10 and 30 for centiles above the $50^{\text {th }}$ percentile before beginning to level around year 40 . The lowest centiles displayed fairly constant slow growth through 50 years. The model displays a range of height between $0.95 \mathrm{~m}\left(3^{\text {rd }}\right.$ percentile $)$ and $6.85 \mathrm{~m}\left(97^{\text {th }}\right.$ percentile $)$ at 50 years. The LMS degrees of freedom producing the best BIC score (16791.5) were 0, 5, and 3 respectively. The fit of the model was significant to a 0.0001 level (Appendix 8). Lambda, sigma, and mu values are reported in the appendices (Appendix 1-4) along with age and height values for each individual centile curve. 


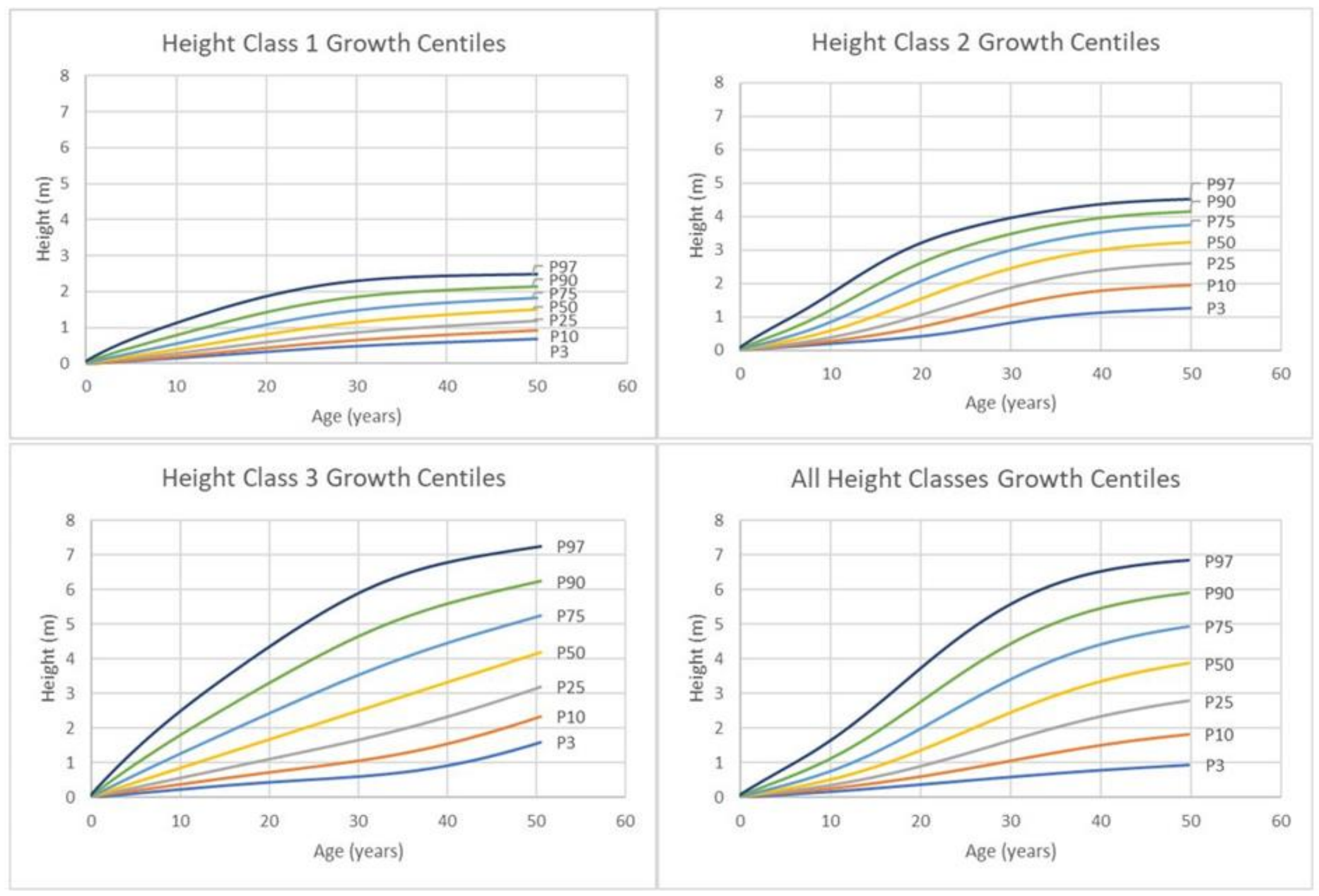

Figure 6: Height class centiles for red spruce modelled in RefCurv (Winkler 2017). 
Mature Tree Overlay

Sample size of overstory red spruce was insufficient and noncontiguous to properly model growth centiles. Twenty-four overstory trees were used as individual overlays to broadly compare how an older cohort grew in a seedling/sapling stage compared to the current understory cohort. Further analyses showed somewhat of a separation in growth rates between mature trees established before and after the year 1900. Fifteen of the twenty-four mature individuals outperformed the $97^{\text {th }}$ percentile in understory height growth by year 50 . Among the mature trees 7 of 24 were never slower growing than the $97^{\text {th }}$ percentile of the understory trees. Eight of 24 mature trees remained below the $50^{\text {th }}$ percentile of understory height growth at 50 years but eventually still reached a dominant or codominant position. The slowest growing individual did not display growth rates above the $10^{\text {th }}$ percentile until after age 70 .

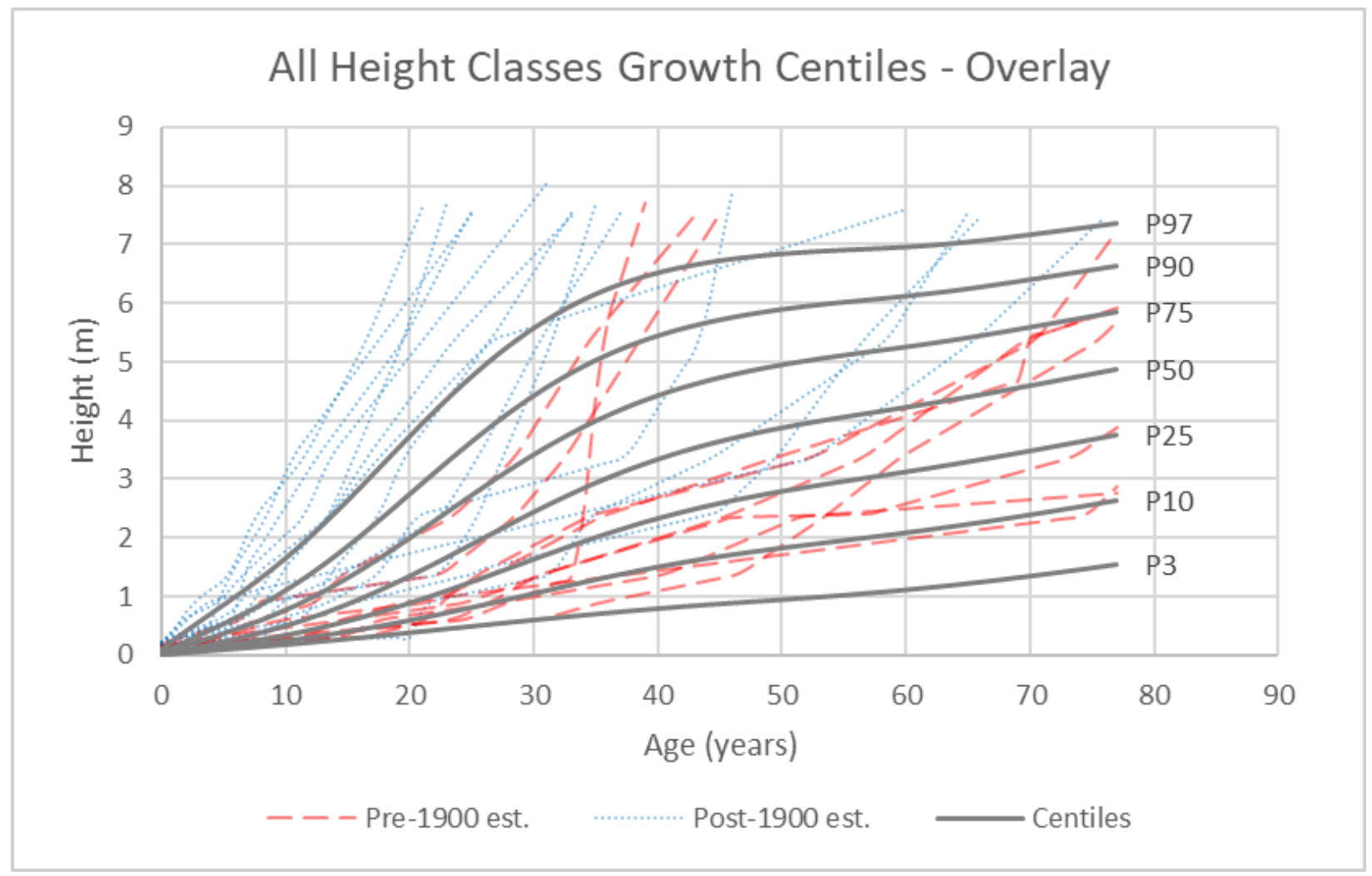

Figure 5: Centiles for height growth by age for all understory red spruce modelled in RefCurv (Winkler et al. 2017) overlaid with early growth of 24 mature dominant and codominant red spruce separated by period of establishment. 


\section{Nonlinear Analysis}

JMP was used to model allometric relationships in understory red spruce. Of the 9 combinations of measurements considered only 3 were modelled based on having significant relationships. Three models were produced using nonlinear analysis. Diameter at breast height (DBH) was used to predict total tree height, DBH was used to predict crown width, and total tree height was used to predict crown width. Multiple fits were assessed and graphed to determine which was best using AIC score. Models with nonsignificant parameters were removed. Nonlinear analysis was also used to predict age using DBH, crown width, and total height respectively.

The following equations were found to be among the top preforming nonlinear models for one or more of the allometric and age relationships:

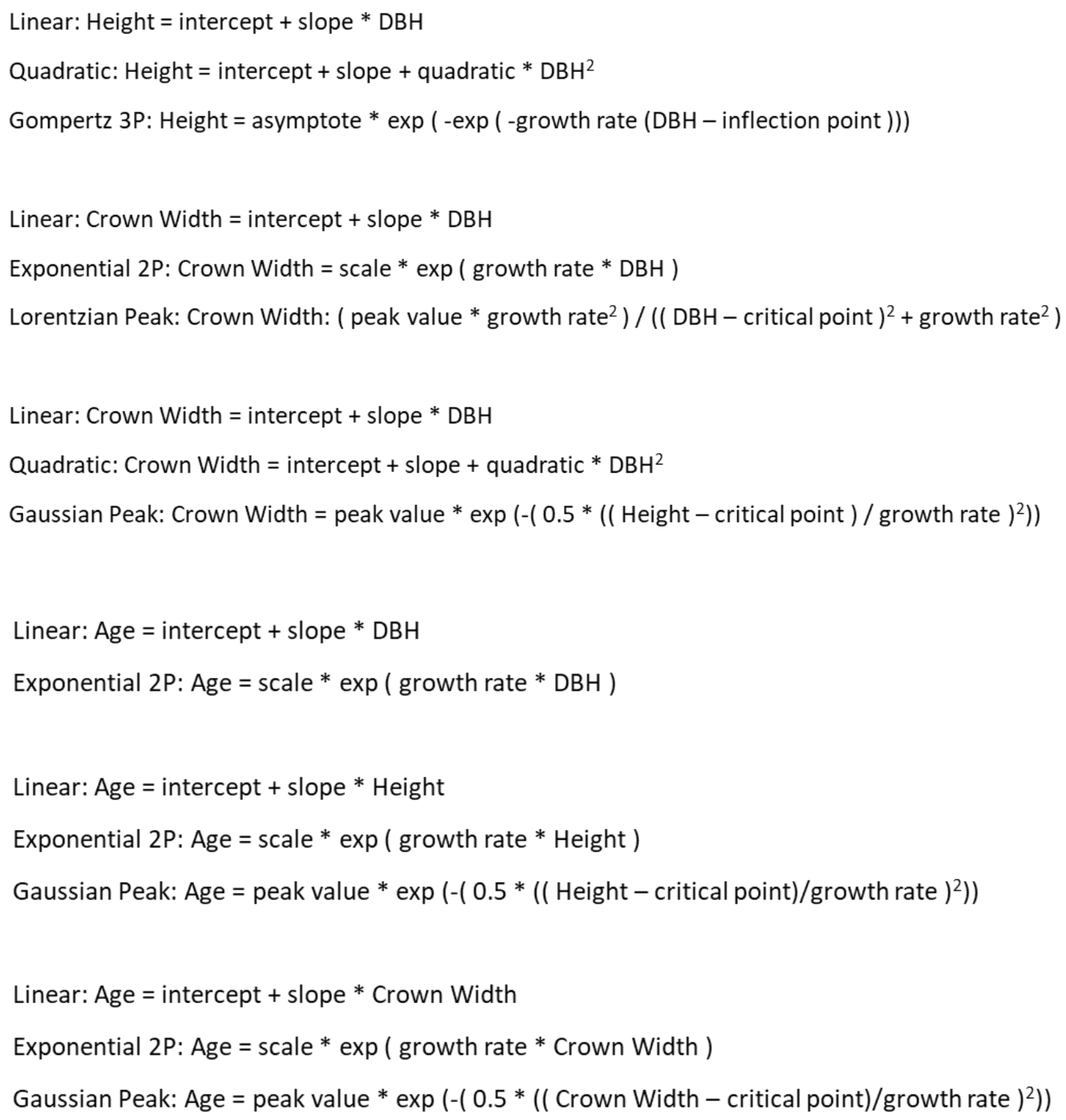




\section{$\underline{\text { Allometric Relationships }}$}

\section{Diameter at Breast Height Predicting Height}

Diameter at breast height used to predict total tree height was the strongest relationship found, resulting in an $\mathrm{R}^{2}$ value of 0.79 . The relationship was best represented using a Gompertz (3P) fit resulting in an AIC score of 439.1 followed closely by quadratic and linear fits. Although a Gompertz (3P) fit had a lower AIC score, it may overpredict the relationship overtime. Both quadratic and linear fits had only slightly lower $\mathrm{R}^{2}$ values but much lower AIC weights. The linear fit predicts a more expected relationship beyond the data points available.

Table 2: Summary of the three best performing nonlinear models developed for the DBH predicting height relationship.

\begin{tabular}{lccccccc}
\hline \multicolumn{1}{c}{ Model } & AIC & AIC Weight & BIC & SSE & MSE & RMSE & R-Square \\
\hline Gompertz 3P & 439.091 & 0.893 & 451.994 & 103.401 & 0.536 & 0.732 & 0.794 \\
Quadratic & 443.363 & 0.105 & 456.266 & 105.679 & 0.548 & 0.740 & 0.789 \\
Linear & 452.070 & 0.001 & 461.779 & 111.661 & 0.576 & 0.759 & 0.778 \\
\hline
\end{tabular}

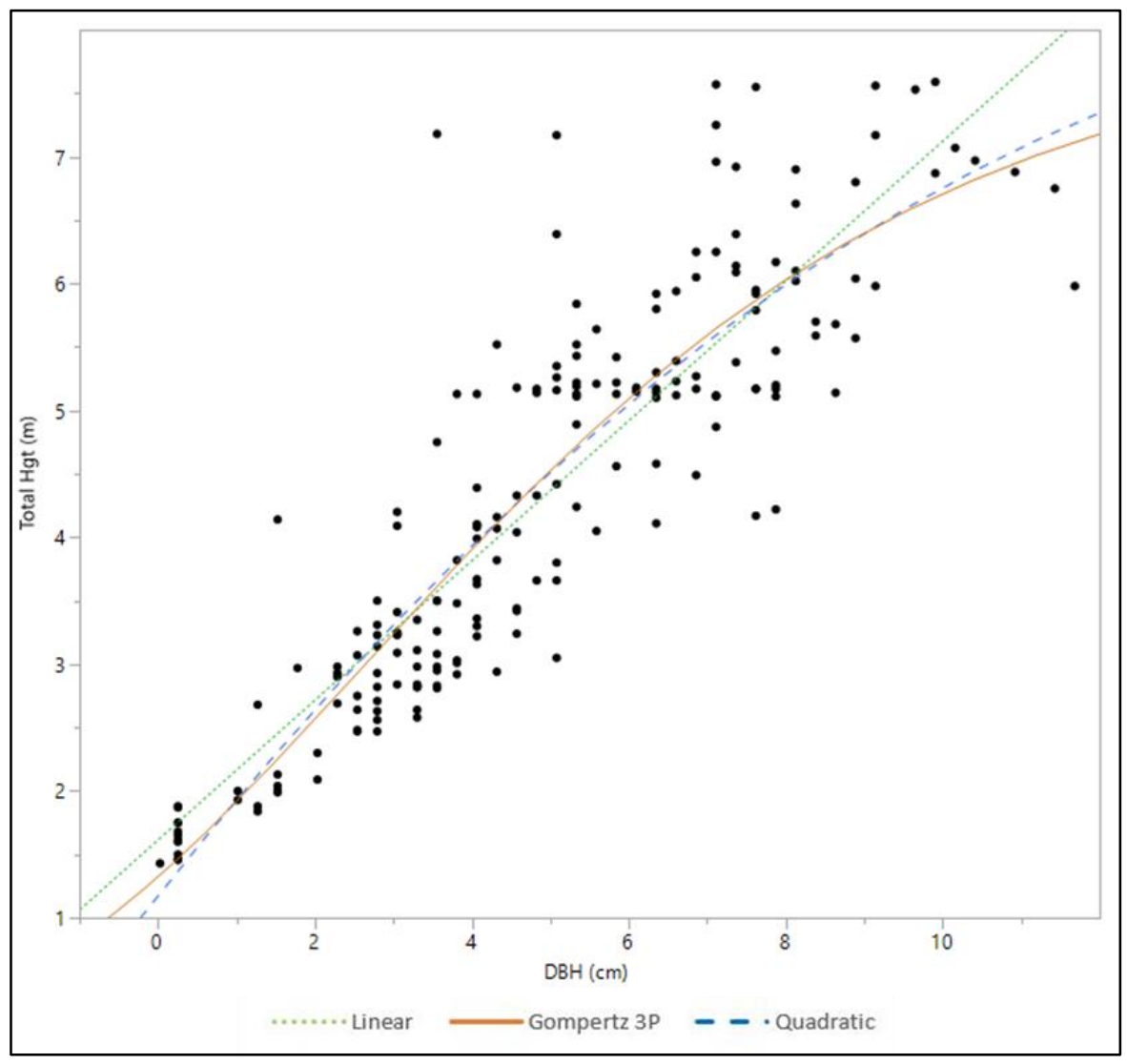

Figure 6: The top three nonlinear models produced using diameter at breast height to predict tree height in understory red spruce. 
Table 3: Model parameters for the three best performing models for the DBH predicting height relationship.

\begin{tabular}{llcccccc}
\hline & & & Std & Wald & Prob $>$ & Lower & Upper \\
& Parameter & Estimate & Error & ChiSquare & ChiSquare & $\mathbf{9 5 \%}$ & $\mathbf{9 5 \%}$ \\
\hline Linear & Intercept & 1.614 & 0.116 & 192.845 & $<.0001$ & 1.386 & 1.842 \\
& Slope & 0.551 & 0.021 & 677.996 & $<.0001$ & 0.509 & 0.592 \\
\hline \multirow{2}{*}{ Quadratic } & Intercept & 1.174 & 0.175 & 45.119 & $<.0001$ & 0.831 & 1.517 \\
& Slope & 0.778 & 0.072 & 117.815 & $<.0001$ & 0.637 & 0.918 \\
& Quadratic & -0.022 & 0.007 & 10.924 & 0.001 & -0.035 & -0.009 \\
\hline \multirow{2}{*}{ Gompertz 3P } & Asymptote & 8.069 & 0.589 & 187.713 & $<.0001$ & 6.914 & 9.223 \\
& Growth Rate & 0.228 & 0.030 & 56.200 & $<.0001$ & 0.169 & 0.288 \\
& Inflection Point & 2.594 & 0.338 & 58.765 & $<.0001$ & 1.931 & 3.257 \\
\hline
\end{tabular}

\section{Diameter at Breast Height Predicting Crown Width}

Diameter at breast height used to predict crown width displayed a significantly weaker relationship $\left(\mathrm{R}^{2}=0.5\right)$. An exponential $(2 \mathrm{P})$ relationship was the best fit producing an AIC score of 241.6. Linear and Lorentzian fits were modelled producing similar $\mathrm{R}^{2}$ values and AIC weights. A linear fit is expected when modelling this relationship. The other models produce less likely scenarios beyond the data points.

Table 4: Summary of the three best performing nonlinear models developed for the DBH predicting crown width relationship.

\begin{tabular}{lccccccc}
\hline Model & AIC & AIC Weight & BIC & SSE & MSE & RMSE & R-Square \\
\hline Exponential 2P & 241.566 & 0.401 & 251.276 & 38.148 & 0.197 & 0.443 & 0.499 \\
Lorentzian Peak & 241.981 & 0.326 & 254.884 & 37.824 & 0.196 & 0.443 & 0.503 \\
Linear & 242.328 & 0.274 & 252.037 & 38.296 & 0.197 & 0.444 & 0.497 \\
\hline
\end{tabular}




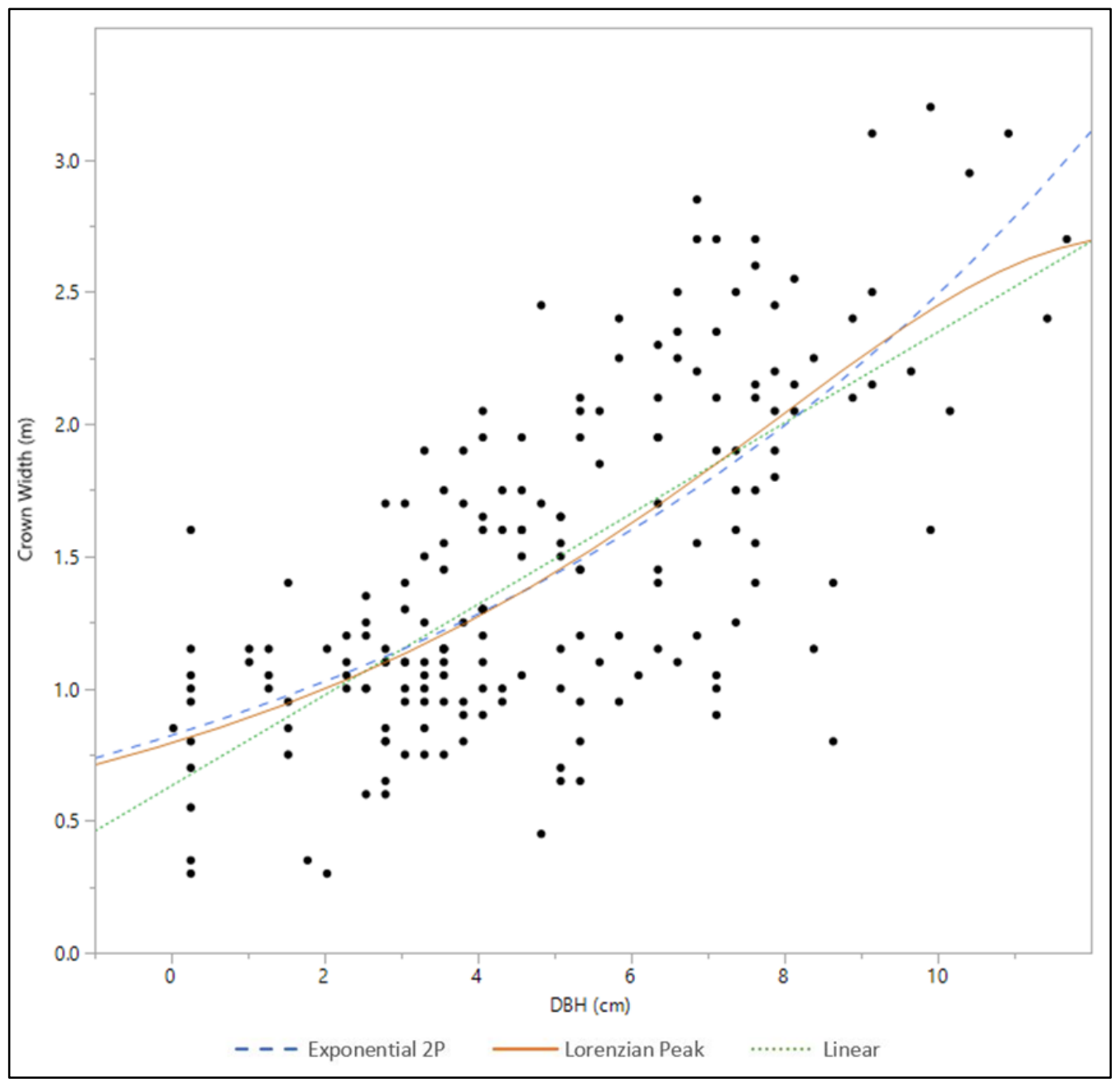

Figure 7: The top three nonlinear models produced using diameter at breast height to predict crown width in understory red spruce.

Table 5: Model parameters for the three best performing models for the DBH predicting crown width relationship.

\begin{tabular}{llcccccc}
\hline & & & Std & Wald & Prob $>$ & Lower & Upper \\
& Parameter & Estimate & Error & ChiSquare & ChiSquare & $\mathbf{9 5 \%}$ & $\mathbf{9 5 \%}$ \\
\hline Linear & Intercept & 0.632 & 0.068 & 86.170 & $<.0001$ & 0.498 & 0.765 \\
& Slope & 0.172 & 0.012 & 191.914 & $<.0001$ & 0.147 & 0.196 \\
\hline \multirow{2}{*}{ Exponential 2P } & Scale & 0.822 & 0.045 & 337.514 & $<.0001$ & 0.734 & 0.910 \\
& Growth Rate & 0.111 & 0.008 & 196.530 & $<.0001$ & 0.095 & 0.126 \\
\hline \multirow{2}{*}{ Lorentzian Peak } & Peak Value & 2.713 & 0.363 & 55.884 & $<.0001$ & 2.002 & 3.425 \\
& Growth Rate & 8.147 & 0.825 & 97.550 & $<.0001$ & 6.531 & 9.764 \\
& Critical Point & 12.676 & 1.697 & 55.819 & $<.0001$ & 9.351 & 16.002 \\
\hline
\end{tabular}




\section{$\underline{\text { Height Predicting Crown Width }}$}

Total height was used to predict crown width producing a Gaussian Peak model with a $\mathrm{R}^{2}$ value of 0.53 . The model achieved an AIC score of 343.3 outperforming quadratic and linear variations. This was the second weakest of the three modelled allometric relationships. The quadratic model only produced a slightly higher AIC score (343.3) and an identical $\mathrm{R}^{2}$ value compared to the best fitting model. A linear relationship is expected when modeling this relationship despite the AIC scores produced using the understory red spruce data.

Table 6: Summary of the three best performing nonlinear models developed for the height predicting crown width relationship.

\begin{tabular}{lccccccc}
\hline Model & AIC & AIC Weight & BIC & SSE & MSE & RMSE & R-Square \\
\hline Gaussian Peak & 343.281 & 0.492 & 357.236 & 55.778 & 0.224 & 0.473 & 0.530 \\
Quadratic & 343.336 & 0.478 & 357.292 & 55.791 & 0.224 & 0.473 & 0.530 \\
Linear & 348.878 & 0.030 & 359.369 & 57.500 & 0.230 & 0.480 & 0.516 \\
\hline
\end{tabular}

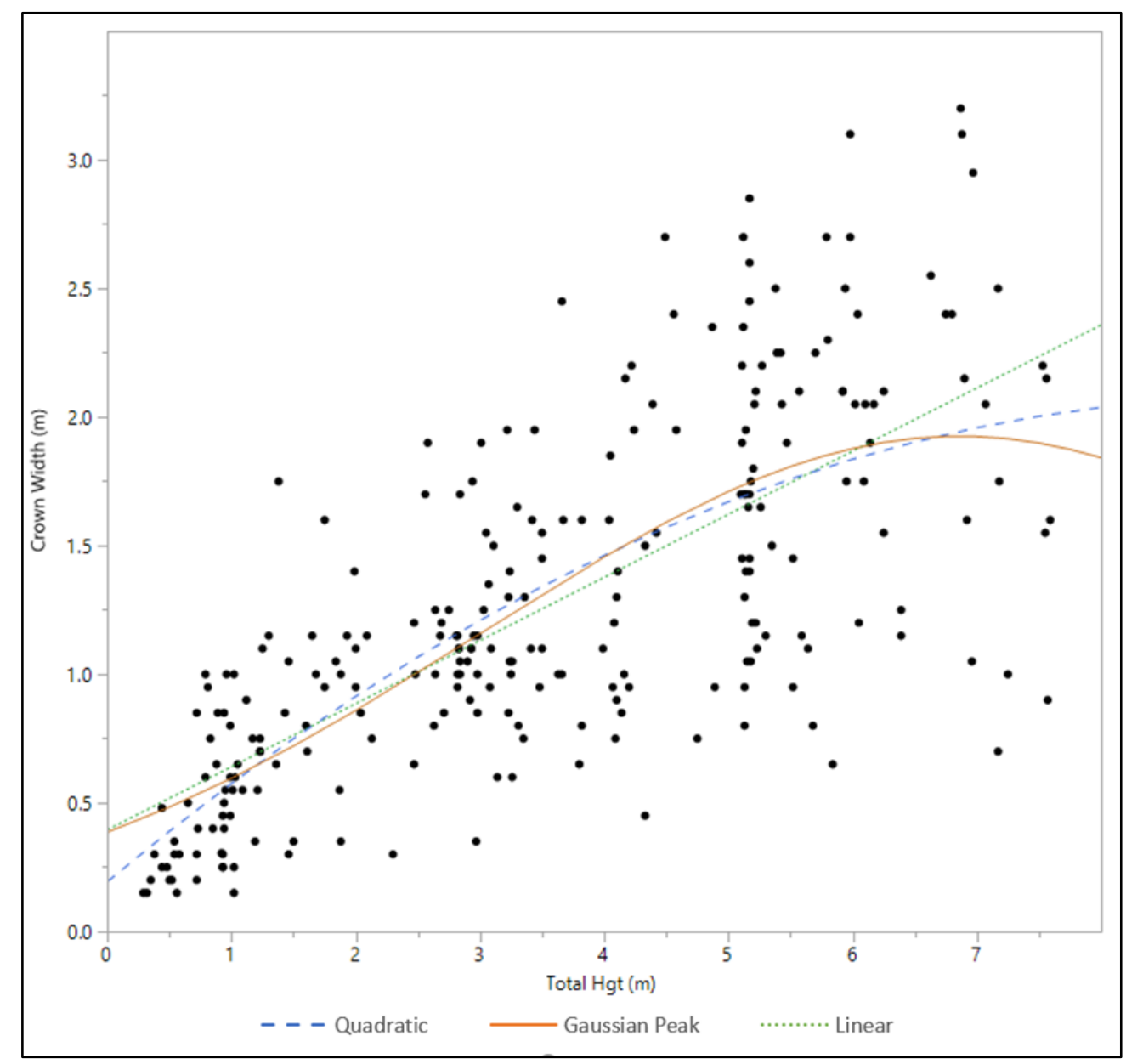

Figure 8: The top three nonlinear models produced using tree height to predict crown width in understory red spruce. 
Table 7: Model parameters for the three best performing models for the height predicting crown width relationship.

\begin{tabular}{llcccccc}
\hline & & & Wald & Prob $>$ & Lower & Upper \\
& Parameter & Estimate & Std Error & ChiSquare & ChiSquare & $\mathbf{9 5 \%}$ & $\mathbf{9 5 \%}$ \\
\hline Linear & Intercept & 0.395 & 0.061 & 41.784 & $<.0001$ & 0.275 & 0.515 \\
& Slope & 0.245 & 0.015 & 266.285 & $<.0001$ & 0.216 & 0.275 \\
\hline \multirow{2}{*}{ Quadratic } & Intercept & 0.193 & 0.095 & 4.158 & 0.041 & 0.008 & 0.379 \\
& Slope & 0.404 & 0.059 & 46.509 & $<.0001$ & 0.288 & 0.520 \\
& Quadratic & -0.022 & 0.008 & 7.631 & 0.006 & -0.037 & -0.006 \\
\hline \multirow{2}{*}{ Gaussian Peak } & Peak Value & 1.926 & 0.079 & 590.037 & $<.0001$ & 1.770 & 2.081 \\
& Critical Point & 6.862 & 0.526 & 170.131 & $<.0001$ & 5.830 & 7.893 \\
& Growth Rate & 3.825 & 0.382 & 100.313 & $<.0001$ & 3.077 & 4.574 \\
\hline
\end{tabular}

$\underline{\text { Age Prediction }}$

Diameter at Breast Height Predicting Age

Diameter at breast height was used to predict age in understory red spruce. The top models produced were exponential (2P) and linear fits. They produced similar $\mathrm{R}^{2}$ values $(0.29)$ as well as AIC scores although an exponential fit was deemed best. This relationship only explained around $29 \%$ of the variation in age using diameter. The scatterplot (Figure 9) shows large variations in ages in trees of a similar diameter highlighting varying year of suppression. Only two models could be produced with significant parameters for this relationship.

Table 8: Summary of the two best performing nonlinear models developed for the DBH predicting age relationship.

\begin{tabular}{lccccccc}
\hline Model & AIC & AIC Weight & BIC & SSE & MSE & RMSE & R-Square \\
\hline Exponential 2P & 1583.478 & 0.745 & 1593.187 & 35880.695 & 184.952 & 13.600 & 0.299 \\
Linear & 1585.623 & 0.255 & 1595.333 & 36275.668 & 186.988 & 13.674 & 0.292 \\
\hline
\end{tabular}




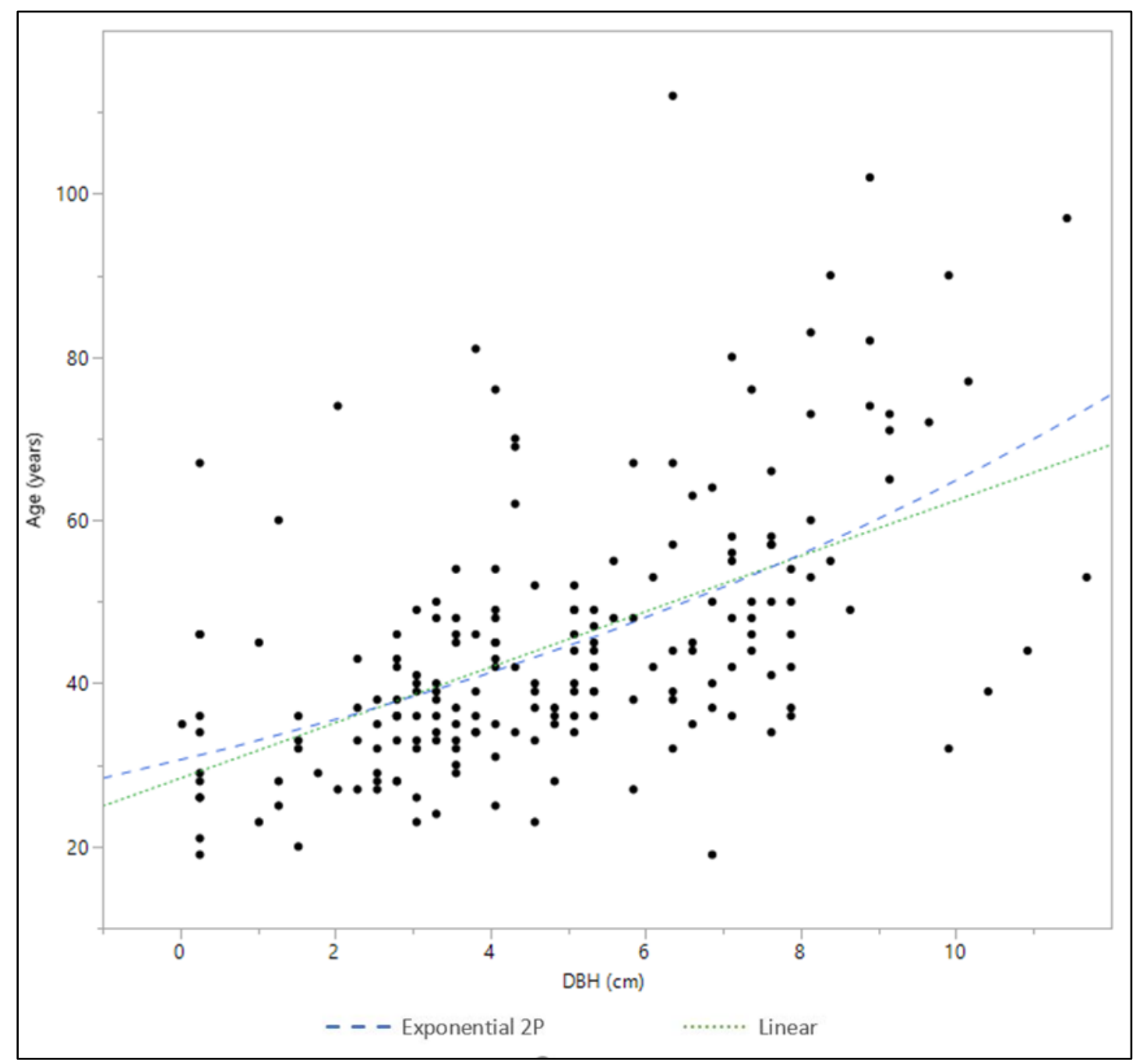

Figure 9: The top two nonlinear models produced using diameter at breast height to predict age in understory red spruce.

Table 9: Model parameters for the two best performing models for the DBH predicting age relationship.

\begin{tabular}{llcccccc}
\hline & & & Std & Wald & Prob $>$ & Lower & Upper \\
& Parameter & Estimate & Error & ChiSquare & ChiSquare & 95\% & $\mathbf{9 5 \%}$ \\
\hline Linear & Intercept & 28.348 & 2.095 & 183.163 & $<.0001$ & 24.243 & 32.454 \\
& Slope & 3.408 & 0.381 & 79.870 & $<.0001$ & 2.660 & 4.155 \\
\hline \multirow{2}{*}{ Quadratic } & Scale & 30.575 & 1.591 & 369.548 & $<.0001$ & 27.458 & 33.693 \\
& Growth Rate & 0.075 & 0.008 & 86.659 & $<.0001$ & 0.059 & 0.091 \\
\hline
\end{tabular}




\section{Height Predicting Age}

Tree height was used to predict age in understory red spruce. A linear fit received the best AIC score (2042.1) followed by a Gaussian peak fit and an exponential (2P) growth model. Similar $\mathrm{R}^{2}$ values were produced ranging from 0.329 to 0.339 resulting in only around $33 \%$ of the variation in age being explained by height. The scatterplot (Figure 10) again shows large variations in ages among trees of a similar height. The trees collected for data analysis met minimum heights of $0.1 \mathrm{~m}$. Extrapolation below these heights, prior to establishment $(15 \mathrm{~cm})$, may not be accurate as biologically the relationship should be constrained to the origin.

Table 10: Summary of the three best performing nonlinear models developed for the height predicting age relationship.

\begin{tabular}{lccccccc}
\hline Model & AIC & AIC Weight & BIC & SSE & MSE & RMSE & R-Square \\
\hline Linear & 2042.141 & 0.642 & 2052.632 & 47623.995 & 190.496 & 13.802 & 0.329 \\
Gaussian Peak & 2043.952 & 0.259 & 2057.908 & 47576.055 & 191.068 & 13.823 & 0.330 \\
Exponential 2P & 2045.882 & 0.099 & 2056.373 & 48336.231 & 193.345 & 13.905 & 0.319 \\
\hline
\end{tabular}

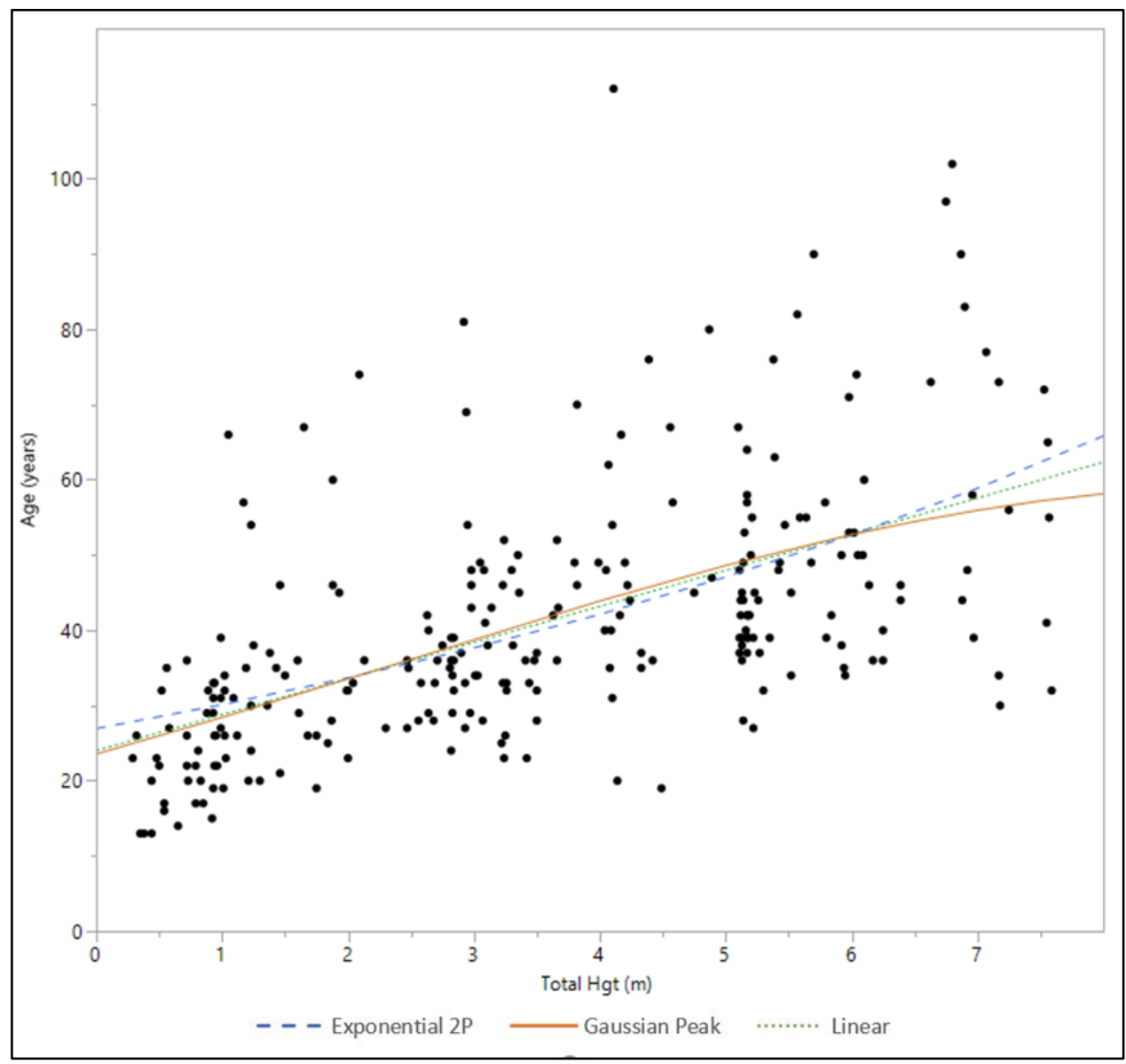

Figure 10: The top three nonlinear models produced using tree height to predict age in understory red spruce. 
Table 11: Model parameters for the three best performing models for the height predicting age relationship.

\begin{tabular}{|c|c|c|c|c|c|c|c|}
\hline & Parameter & Estimate & $\begin{array}{c}\text { Std } \\
\text { Error }\end{array}$ & $\begin{array}{c}\text { Wald } \\
\text { ChiSquare }\end{array}$ & $\begin{array}{c}\text { Prob > } \\
\text { ChiSquare }\end{array}$ & $\begin{array}{c}\text { Lower } \\
95 \%\end{array}$ & $\begin{array}{c}\text { Upper } \\
95 \%\end{array}$ \\
\hline \multirow[t]{2}{*}{ Linear } & Intercept & 24.007 & 1.758 & 186.482 & $<.0001$ & 20.562 & 27.453 \\
\hline & Slope & 4.796 & 0.433 & 122.758 & $<.0001$ & 3.948 & 5.644 \\
\hline \multirow[t]{2}{*}{ Exponential 2P } & Scale & 26.938 & 1.388 & 376.579 & $<.0001$ & 24.217 & 29.659 \\
\hline & Growth Rate & 0.112 & 0.011 & 109.922 & $<.0001$ & 0.091 & 0.133 \\
\hline \multirow[t]{3}{*}{ Gaussian Peak } & Peak Value & 59.201 & 8.435 & 49.255 & $<.0001$ & 42.668 & 75.734 \\
\hline & Critical Point & 9.298 & 2.756 & 11.380 & 0.001 & 3.896 & 14.701 \\
\hline & Growth Rate & 6.848 & 1.779 & 14.820 & 0.000 & 3.362 & 10.335 \\
\hline
\end{tabular}

\section{Crown Width Predicting Age}

Finally, crown width was used to predict age in understory red spruce. Similarly, low $\mathrm{R}^{2}$ values of $0.293-0.302$ were produced for the three best preforming models. A linear fit was deemed best based on the lowest AIC score of 2052.1 compared to the exponential (2P) and Gaussian peak fits. Still only $30 \%$ of the variation in age was attributed to crown size in the linear fit. The scatterplot (Figure 11) displays large variations in crown sizes for trees of similar age.

Table 12: Summary of the three best performing nonlinear models developed for the crown width predicting age relationship.

\begin{tabular}{lccccccc}
\hline Model & AIC & AIC Weight & BIC & SSE & MSE & RMSE & R-Square \\
\hline Linear & 2052.117 & 0.655 & 2062.608 & 49547.095 & 198.188 & 14.078 & 0.302 \\
Gaussian Peak & 2054.360 & 0.213 & 2068.316 & 49582.140 & 199.125 & 14.111 & 0.302 \\
Exponential 2P & 2055.327 & 0.132 & 2065.819 & 50182.350 & 200.729 & 14.168 & 0.293 \\
\hline
\end{tabular}




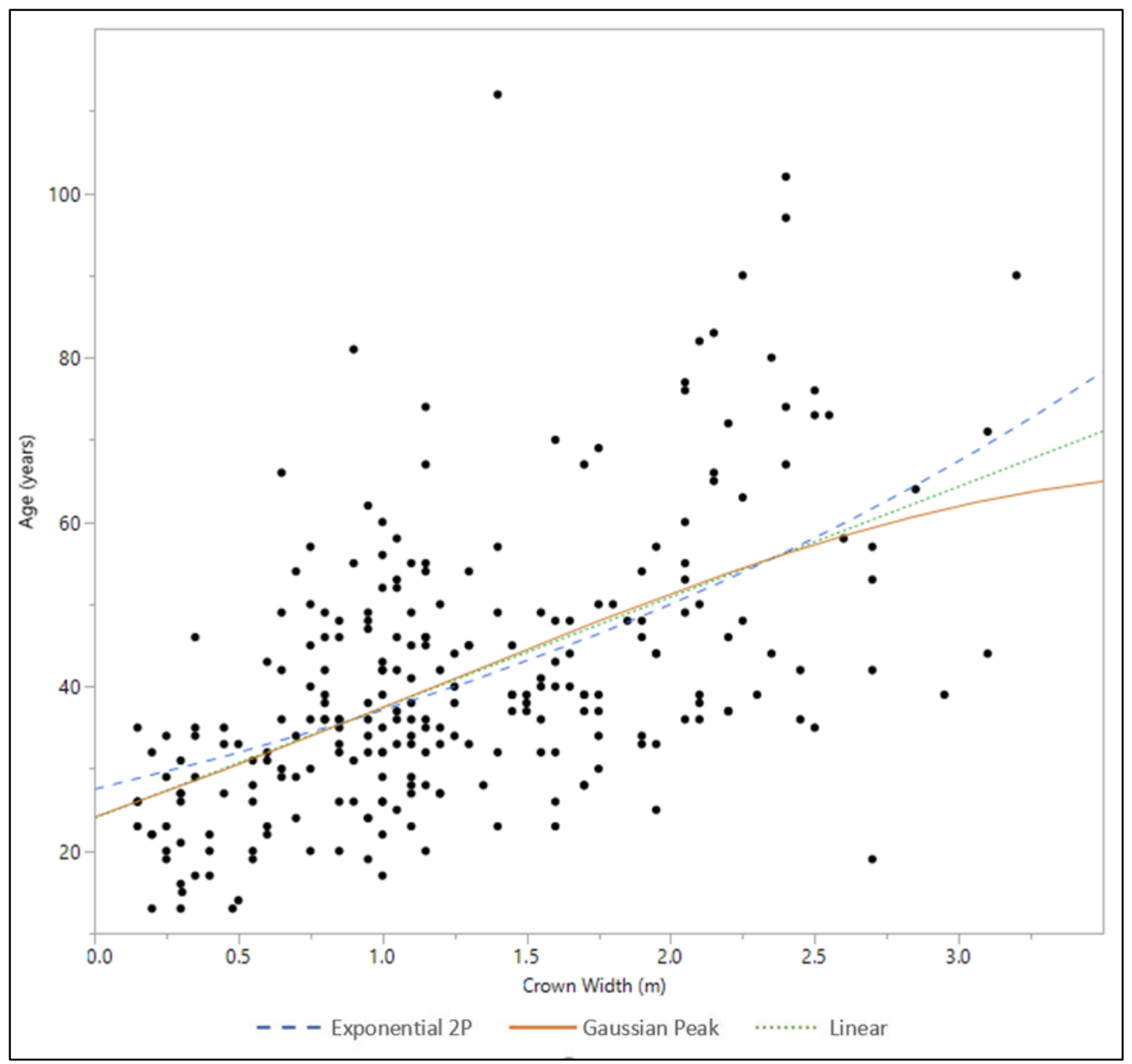

Figure 11: The top three nonlinear models produced using crown width to predict age in understory red spruce.

Table 13: Model parameters for the three best performing models for the crown width predicting age relationship.

\begin{tabular}{llcccccc}
\hline & & & & Wald & Prob $>$ & Lower & Upper \\
& Parameter & Estimate & Std Error & ChiSquare & ChiSquare & $\mathbf{9 5 \%}$ & $\mathbf{9 5 \%}$ \\
\hline Linear & Intercept & 23.980 & 1.855 & 167.100 & $<.0001$ & 20.345 & 27.616 \\
& Slope & 13.444 & 1.292 & 108.290 & $<.0001$ & 10.912 & 15.976 \\
\hline \multirow{2}{*}{ Exponential 2P } & Scale & 27.506 & 1.370 & 403.048 & $<.0001$ & 24.821 & 30.191 \\
& Growth Rate & 0.299 & 0.029 & 108.420 & $<.0001$ & 0.243 & 0.355 \\
Gaussian Peak & Peak Value & 65.981 & 13.691 & 23.226 & $<.0001$ & 39.147 & 92.815 \\
& Critical Point & 4.002 & 1.445 & 7.666 & 0.006 & 1.169 & 6.835 \\
& Growth Rate & 2.820 & 0.848 & 11.066 & 0.001 & 1.158 & 4.481 \\
\hline
\end{tabular}




\section{Regional Comparisons}

\section{Diameter at Breast Height Predicting Height}

Nonlinear analysis was carried out on diameter at breast height predicting tree height. Separate linear fits were used on samples larger and smaller than three inches in diameter to compare the relationship with the Curtis-Arney (Curtis 1967; Arney 1985) equations used in the Forest Vegetation Simulator (FVS) parameterized for red spruce using the NE variant. Two equations are utilized creating a separation at $7.62 \mathrm{~cm}$ ( 3 inches) between larger and smaller trees. The linear relationship developed using sampled understory red spruce differed only slightly for trees below $7.62 \mathrm{~cm}$ in diameter. The slope in the predicted Curtis-Arney line has a larger slope and smaller intercept compared to the actual data. The relationship in trees with diameters larger than $7.62 \mathrm{~cm}$ shows larger differences. The predicted line using the CurtisArney equation displays a much larger slope and smaller intercept compared to the actual data. Sampled red spruce underperformed compared to the Curtis-Armey equations. The sample size for trees above three inches in diameter $(n=28)$ is much smaller compared to those less than 3 inches $(n=224)$ possibly influencing the differences.

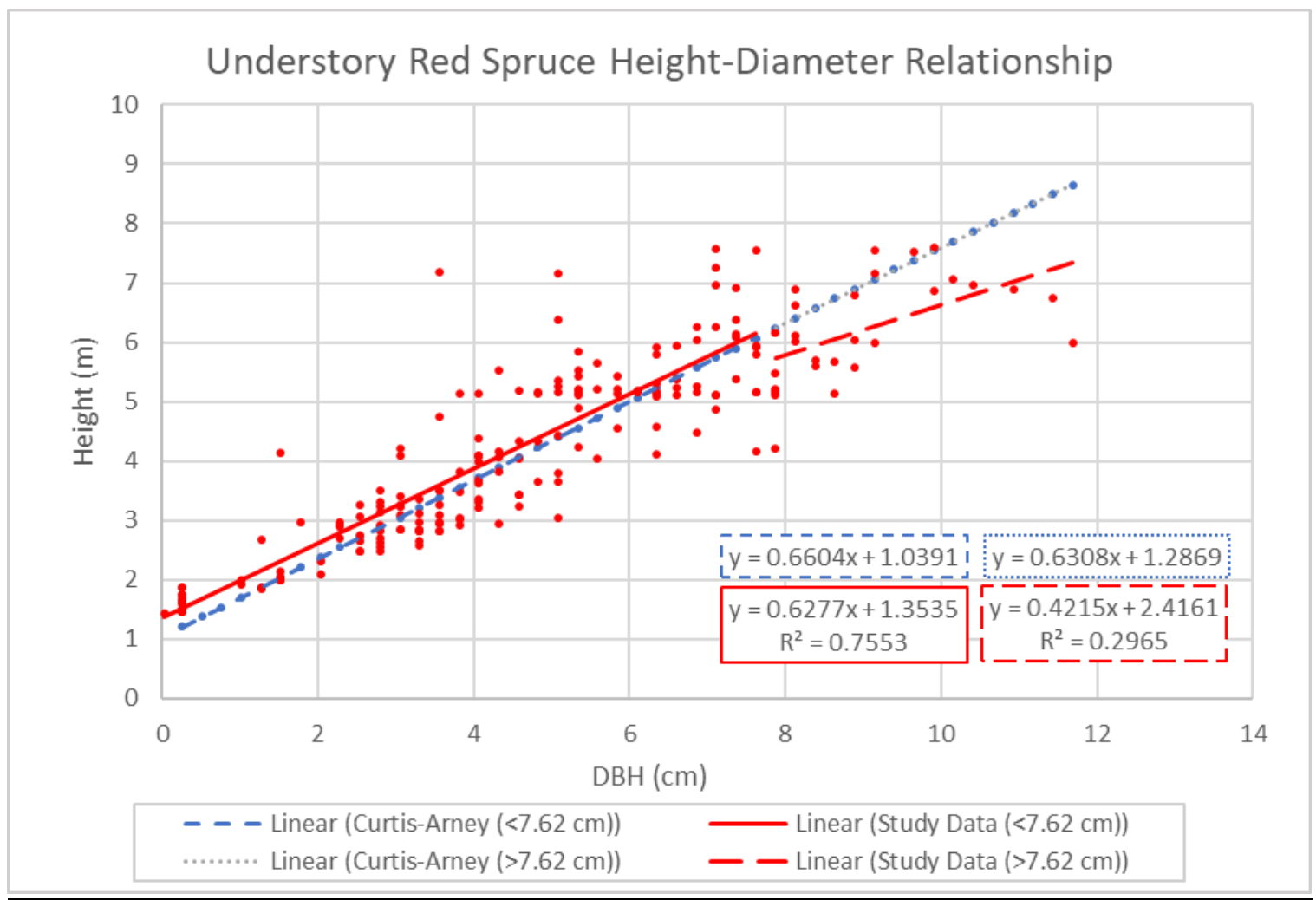

Figure 12: Comparison of diameter at breast predicting tree height using the Curtis-Arney equations and the linear models developed for understory red spruce in this study. 


\section{Diameter at Breast Height Predicting Crown Width}

Another comparison was carried out on the allometric relationship using diameter at breast height to predict crown width. A power equation developed by Bechtold (2003) from plots across the range of red spruce in the United States was compared to the linear equation developed using the sampled understory red spruce. The local equation consistently produced slightly larger crown widths (about $0.5 \mathrm{~m}$ larger) compared to the equation from Bechtold. The difference in the lines decreased with larger diameters. Using a power equation on the understory red spruce data, only $35 \%$ of the variation in crown width could be explained by diameter size. The linear fit, one of the best models, compared to nonlinear analysis, improved the $\mathrm{R}^{2}$ value (0.497).

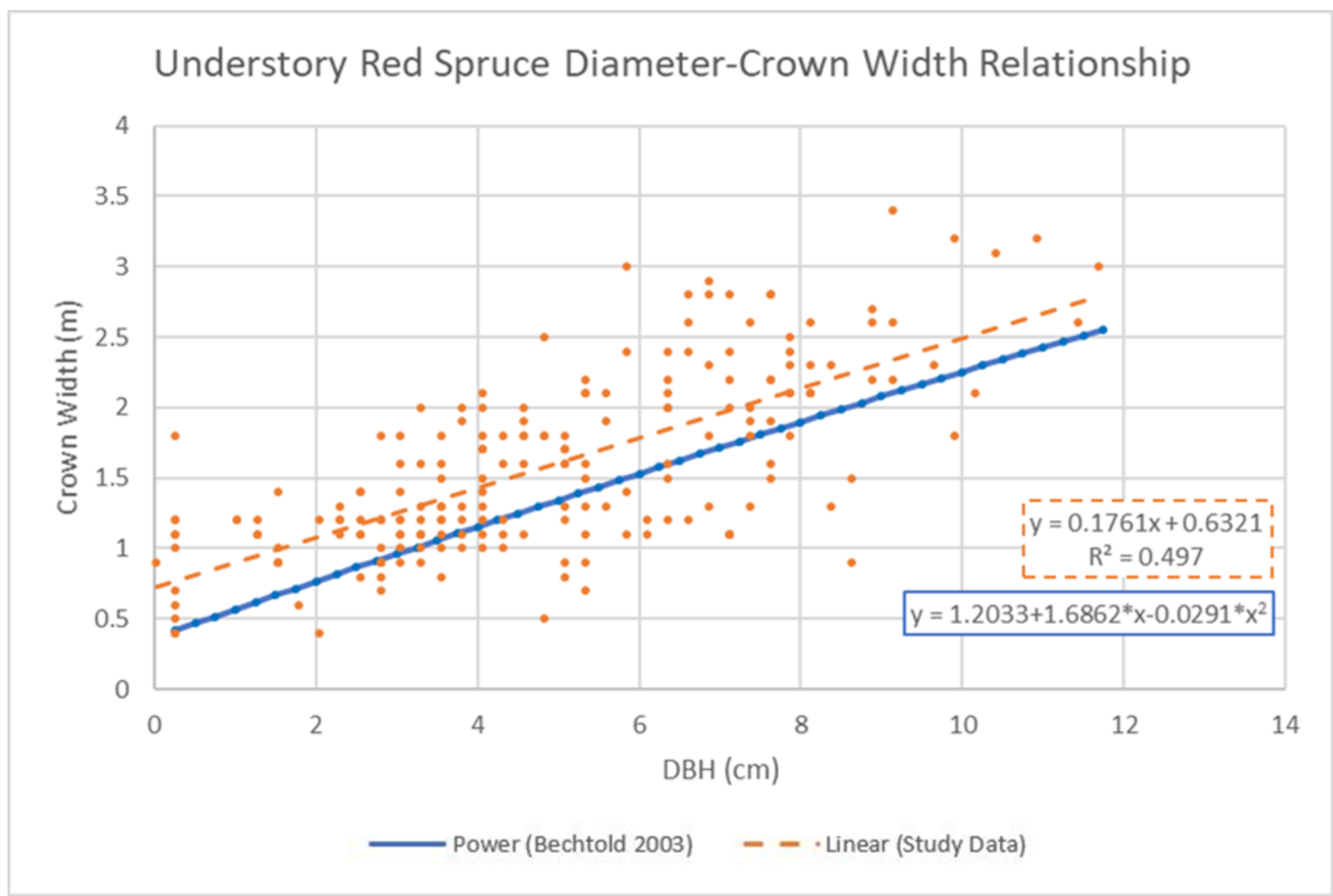

Figure 13: Comparison of diameter at breast height predicting crown width using the equation developed by Bechtold (2003) and the linear model developed using understory red spruce data from this study. 


\section{DISCUSSION}

\section{Reference Curves}

\section{Understory Height Classes}

Sampling of understory red spruce was separated into three height classes to capture the variation in young trees prior to ascension into the canopy. Although shorter height classes displayed a lower mean age, the age range across the three height classes was similar, which suggested that trees established during the same period were having different growth rates likely attributed to their location in the stand. Growth rates are influenced by a number of factors including competition. Sampled trees were most commonly found under mature red spruce and a variety of northern hardwoods. Red spruce is long lived but its canopy and associated soils may produce more suitable microclimates for young trees to outlast faster growing hardwoods (Baldwin 1933; Dumias and Prevost 2016; Greenwood et al. 2008). Northern hardwoods can compete with understory red spruce (Cogbill and White 1991), but yield gaps more frequently (Rentch et al. 2010).

Although red spruce mortality has been widely studied through periods of decline (Mielke 1986; Johnson et al. 1988; McLaughlin et al. 1987; Hamburg and Cogbill 1988), it is less commonly researched in the seedling and sapling stages (Busing and Wu 1990; Dumais et al. 2019). Centiles produced for height class 1 displayed the least variation in height compared to the other classes. Only the $3^{\text {rd }}$ and $10^{\text {th }}$ percentiles in height class 1 displayed shorter heights than the lowest centile in height class 2 . Given that this is survivor-only data, most of these individuals are likely to experience mortality prior to advancing to the next height class. The reference curves do indicate that a small portion of seedlings are able to persist with slow growth. This is supported by Busing and Wu's (1990) work with red spruce in the Southern Appalachians where mortality in small trees was $0.7 \%$ annually. The $50^{\text {th }}$ percentile in height class 1 yields a similar height to the $3^{\text {rd }}$ percentile in height class 3 . Around half of the trees in height class 1 are therefore able, yet may be unlikely, to persist into height class 3 , albeit as the slowest growing in that class. Even the $97^{\text {th }}$ percentile in height class 1 only produces similar height to the $10^{\text {th }}$ percentile in height class 3 at 50 years. This suggests that the range of individuals in height class 1 have a chance to reach height class 3 but a majority are likely to experience mortality prior to release into the overstory. Given the observed rates in the Southern Appalachians annually (Busing and Wu 1990), a large majority of these individuals would succumb to mortality prior to 50 years of age.

Height class 2 produces a range of heights greater than height class 1 after 50 years. The fastest growing centile $\left(97^{\text {th }}\right.$ percentile) produces similar heights to average trees $\left(50^{\text {th }}\right.$ percentile) in height class 3 . Only the $3^{\text {rd }}$ percentile in height class 2 yields a shorter tree than the $3^{\text {rd }}$ percentile in height class 3 . This indicates the ability of nearly all trees in height class 2 to advance into height class 3 prior to mortality. This would suggest lower mortality rates in larger trees when comparing height class 2 to height class 1 where the lowest 10 percent of trees were 
unable to advance into the next class. This drop in mortality as red spruce increases in size is supported by the literature (Busing and Wu 1990). Even so, both smaller height classes show the ability to persist in the understory with slow growth which is expected in shade-tolerant species like red spruce.

Height class 3 displays the most variation in height obtained after 50 years in its centiles. Higher centiles display more vertical in growth indicating unimpeded conditions. Still growth slows as 50 years are modelled. Very few of the understory spruce trees that were sampled occurred in gaps, which would likely support the decline in growth until future release events. It is possible that growth rates will increase again with a release event, but this class was the largest sampled and any additional release would likely begin approaching lower canopy layers. The absence of faster growth rates in height classes 1 and 2 may be a product of the recent lack of disturbance in red spruce habitat on public lands in the region. Most sites appeared to only display sporadic windthrow. This theory of lack of disturbance is supported by the small number of samples taken from gaps during the study and is consistent with other datasets (Lutz 2018; Rentch et al. 2007).

Mature Tree Overlay

A goal of this study was to compare early growth in successful red spruce to growth in understory red spruce today. A limited sample size for dominant and codominant red spruce precluded the development of significant growth centile models. These trees were instead overlaid on centiles built using all sampled understory height classes.

The variation in height growth among mature spruce was larger than any understory height class centiles. The fastest growing individuals outperformed the $97^{\text {th }}$ percentile of the composite model immediately indicating open growth or different resource availability from the time of establishment. The slowest growing individuals barely outperformed the $10^{\text {th }}$ percentile for understory spruce. This may indicate that only the slowest growing understory samples, below the $10^{\text {th }}$ percentile, are not able to persist long enough to experience release into the overstory. Fifteen of twenty-four individuals outperformed the $97^{\text {th }}$ percentile by year $50.75 \%$ of mature trees outperformed the $97^{\text {th }}$ percentile by year 80 meaning most trees with a chance of success will be released by that age. Still $25 \%$ of successful trees will persist in the understory beyond that point. This slower pathway to success is supported by other regional studies (Rentch et al. 2007; Rentch et al. 2016; Wu et al. 1999). Gap creation that produced a canopy release resulted in success for individual red spruce. However, continuous open growth was absent in these cases (Wu et al. 1999).

A distinct pattern can be seen in the sampled mature spruce. Fifteen individuals displayed more open growth when young while 9 individuals experienced slower growth. These differences in growth are likely attributed to competition and disturbance in the stand early in their life history. Trees were separated based on year of establishment. Seven of 10 trees established prior to 1900 were slower growing. Eleven of 14 trees established after 1900 
experienced what appears to be open growth. This difference in growth pattern by year of establishment could be a product of logging. Most red spruce in the region was logged in the late 1800s with fewer remnant stands being logged in the early 1900s. This would make it more likely that trees established prior to 1900 had a canopy overhead in their youth. Later releases could be attributed to their stands being logged. These trees were likely too small for harvest and left as residuals. Trees established after 1900 may have been located in cut over areas from time of establishment producing open growth conditions. Without detailed site histories this cannot be confirmed but used as a possible explanation of the differences in growth.

\section{Nonlinear Analysis}

\section{$\underline{\text { Allometric Relationships }}$}

The height-diameter relationship was by far the strongest of any allometric relationship that was assessed. The height of understory red spruce can be predicted by a diameter measurement with reasonable accuracy. Crown relationships were less predictable. Using diameter or height to predict crown width produced an $\mathrm{R}^{2}$ value lower than what may be expected for many species. Red spruce is unique in its ability to persist for long periods in the understory. Most individuals are under varying degrees of stress including that induced by low light levels. Small crowns are able to sustain individuals until a release or mortality event occurs. Due to varying degrees of stressors and light conditions it becomes hard to predict crown size with a single, easily attained measurement. Similar difficulties were noted for other shadetolerant species, both regionally in the Appalachians and beyond in tropical species (Dawkins 1963; Shallenberger et al. 1986; Hemery et al. 2005). Red spruce in early stages of life may not be an ideal candidate to use allometric relationship as predictors. Practically, the strength of the height-diameter relationship could at least be used to quickly obtain a height estimate.

\section{Using Allometric Measurements to Predict Age}

Ideally a specific growth rate could be identified in past successful individuals and compared to a young trees growth rate today to identify good candidates for management efforts. The 24 destructively sampled red spruce spanned the range of understory growth rates present today. Unfortunately, this does not allow us to identify trees that have a high probability of reaching the canopy. Inversely, this does not rule out most understory trees from doing so, although we understand that most will not reach the canopy based on mortality studies (Busing and $\mathrm{Wu}$ 1990). A common thread in many past successful individuals is an early period of sustained, rapid growth meaning younger trees reaching taller heights in the understory quickly have a good chance to advance into taller height classes. Evidence for this theory of younger trees more successfully responding to release is supported by findings that the response of older individuals declines with age (Brix and van den Driessche 1977). Therefore, identifying age in understory trees could allow us to focus resources on the best individuals. The practical issue of identifying age without destructively sampling then becomes the goal. An easily obtainable 
measurement in the field helping us identify tree age would be of use in management to allocate resources to individuals more likely to succeed in years to come.

Using diameter at breast height, height, and crown width to predict age proved to be difficult. Diameter at breast height predicting age was the strongest identified relationship explaining around $40 \%$ of the variation in age with diameter. This is still a weak relationship. The relationship becomes more unpredictable as age increases. Red spruce seedlings can survive for extended periods of time, even with very little diameter growth (Hart 1965). This feature leads to the same challenges when comparing height-age and crown diameter-age relationships where the $\mathrm{R}^{2}$ values are even lower. These are the difficulties faced when modelling growth for a shade-tolerant species like red spruce. It is likely that this species is not a good candidate for models involving annual growth in the understory.

\section{Regional Comparisons}

When using a growth model an important question to ask is how the model was developed. This includes the time period, the sites, and the sampled trees used to develop said model. Since red spruce was depleted in the Central Appalachians prior to many models being developed, it is likely that current literature does not accurately represent how the species behaves in the region. Additional anthropogenic factors including climate change, disturbance, and pollution could impact the species as well. It is important to identify if red spruce in West Virginia aligns with widely used models. And if not, we may be able to develop a more regionally specific alternative for management purposes.

Two additional models for red spruce growth were identified in the literature. The Forest Vegetation Simulator (FVS) program developed by the USDA Forest Service (Dixon et al. 2008) models the height-diameter relationship using the Curtis-Arney (Curtis 1967, Arney 1985) equations. Trees below $7.62 \mathrm{~cm}$ in diameter performed nearly identical to the predicted equation. Deviations began to occur in trees above that $7.62 \mathrm{~cm}$ diameter split. Sampled red spruce underperformed the equation. These differences may be explained when considering differences in site conditions in larger diameter trees. Individuals experiencing competition and low light levels may continue to add diameter growth at disproportionate rates compared to height growth. Additionally, sample size for trees above a 3-inch diameter was significantly smaller than below that split. A larger sample size could plausibly produce a different result. Additional investigation into Curtis and Arney's work revealed the equation form was developed using western Douglas-fir stands. Although shade-tolerant species were used, the conditions deviate significantly from red spruce stands of the Central Appalachians. For these reasons the accuracy of predictions are more impressive.

The second model compared was developed by Bechtold (2003) using FAI data. He used trees that spanned 24 eastern states including the whole range of red spruce in the United States. Only open grown trees were eliminated to create a sample representative of stand grown trees. Only trees above $12.7 \mathrm{~cm}$ in diameter were measured. This varies from conditions used in our 
study. Red spruce samples were obtained from the understory and no individual met a $12.7-\mathrm{cm}$ diameter. The underperformance of the data when comparing to the model is likely explained by these differences in methodology.

\section{CONCLUSION}

Red spruce has experienced an array of challenges in the Central Appalachians ranging from exploitative practices to changes in climate and competition. Furthering our understanding of how the species develops in the region can help inform management decisions to meet restoration goals. More concrete measures of success are necessary to evaluate our efforts. Understanding how successful trees developed in early stages of life can help quantify which other young trees that have similar potential to ascend into the upper canopy. Additionally, identifying young trees with the allometric measures to meet this quantified success is necessary in management.

This study suggests that understory red spruce today can persist in the forest floor for decades without release or can experience growth matching that of most competitors given the right conditions. Development today is similar to many successful individuals that established prior to the turn of the twentieth century which span most percentiles produced in analysis. Development after that point was revealed to be more rapid. It is apparent that faster growth is more likely to result in a successful tree, but slow growing individuals are able to experience release to reach the same fate. There are multiple pathways for these shade-tolerant individuals to reach the canopy.

Diameter at breast height was found to be the most reliable predictor of tree height and crown width. The relationship between height and crown width was slightly weaker. Predicting age with any of these measures was found to be unreliable. Difficulty in age prediction in shadetolerant understory red spruce is a result of the variation seen in trees of the same sizes. Given the range of successful development, these allometric measures may not be necessary for selecting an individual with the ability to release in the future. Developed equations were found to underperform allometric predictors used in literature. It is possible that a different methodology may be necessary to predict these relationships regionally. 


\section{REFERENCES}

Abbott, H.G., and A.C. Hart. 1960. Mice and voles prefer spruce seeds. USDA Forest Service, Station Paper 153. Northeastern Forest Experiment Station, Upper Darby, PA. 12 p.

Adams, H., and S. Stephenson. 1989. Old-growth red spruce communities in the midAppalachians. Vegetatio. 85(1): 45-56.

Adams, H.S., S.L. Stephenson, T.J. Blasing, and D.N. Duvick. 1985. Growth-trend declines of spruce and fir in mid-Appalachian subalpine forests. Environmental and Experimental Botany 25(4): $315-325$

Allard, H.A., and E. C. Leonard, 1952. The Canaan and the Stony river valleys of West Virginia, Their former magnificent spruce forests, their vegetation and floristics today. Castanea 17(1): 1.

Allen, M.G., and H.E. Burkhart. 2015. A comparison of alternative data sources for modeling site index in loblolly pine plantations. Canadian Journal of Forest Research. 45(8): 10261033.

Arney, J.D. 1985. A modeling strategy for the growth projection of managed stands. Canadian Journal of Forest Research 15(3): 511-518.

Bailey, C.M., and S. Ware. 1990. Red spruce forests of Highland County, Virginia: biogeographical considerations. Castanea. 55(4): 245-258.

Baldwin, H.I. 1933. The density of spruce and fir reproduction related to the direction of exposure. Ecology. 14(2): 152-156

Beane, N.R., J.S. Rentch, and T.M. Schuler. 2013. Using maximum entropy modeling to identify and prioritize red spruce forest habitat in West Virginia. Research Paper NRS-23. Newtown Square, PA: U.S. Department of Agriculture, Forest Service, Northern Research Station. $16 \mathrm{p}$.

Bechtold, W. A. (2004). Largest-crown-width prediction models for 53 species in the western United States. Western Journal of Applied Forestry, 19(4): 245-251.

Blum, B.M. 1990. Picea rubens Sarg. (Red Spruce). P. 250-259 in Silvics of North America, R.M. Burns, and B.H. Honkala (eds.). United States Department of Agriculture, Forest Service. Washington, D.C. 
Brix, H. R., and R. van den Driessche. 1977. Use of rooted cuttings in reforestation: a review of opportunities, problems, and activities. British Columbia Forest Service/Canadian Forestry Service, Joint Report 6. Ottawa, ON. 16 p.

Brown, J., S. Chhin, and E.L. Yetter. Unpublished. Modeling site index of red spruce (Picea rubens) within a changing climate.

Burns, R.M., and B.H. Honkala. 1990. Silvics of North America: 1. Conifers. Agriculture Handbook 654. U.S. Department of Agriculture, Forest Service, Washington, DC. vol.2, $877 \mathrm{p}$.

Busing, R. T., and X. Wu. 1990. Size-specific mortality, growth, and structure of a Great Smoky Mountains red spruce population. Canadian Journal of Forest Research, 20(2): 206-210.

Carmean, W.H. 1972. Site index curves for upland oaks in the Central States. Forest Science, 18(2), 109-120.

Carter, D.R., R.S. Seymour, S. Fraver, and A. Weiskittel. 2017. Reserve tree mortality in two expanding-gap silvicultural systems 20 years after establishment in the Acadian forest of Maine, USA. Forest Ecology and Management. 389: 149-157.

Clarkson, R.B. 1964. Tumult on the mountains: lumbering in West Virginia: 1770-1920. McClain Printing, Parsons, WV. 410 p.

Cogbill, C.V. and P.S. White. 1991. The latitude-elevation relationship for spruce-fir forest and treeline along the Appalachian Mountain chain. Vegetatio 94:153-175.

Curry, B. 2020. The influence of age and sex on measures of body size in captive chimpanzees (Pan troglodytes) cared for in African wildlife sanctuaries and zoological collections. $\mathrm{PhD}$ dissertation, Cardiff Metropolitan University, Cardiff, Wales.

Curtis, R.O. 1967. Height-diameter and height-diameter-age equations for second-growth Douglas-fir. Forest Science 13(4): 365-375.

Dawkins, H.C. 1963. Crown diameters: their relation to bole diameter in tropical forest trees. Commonwealth Forestry Rev. 42, 318-333.

Delcourt, P.A., and H.R. Delcourt. 1984. Late quaternary paleoclimates and biotic responses in eastern North America and the western North Atlantic Ocean. Palaeogeography, Palaeoclimatology, Palaeoecology, 48(2-4), 263-284. 
Dibble, A.C., J.C. Brissette, and M.L. Hunter Jr. 1999. Putting community data to work: some understory plants indicate red spruce regeneration habitat. Forest Ecology and Management. 114: 257-291.

Dixon, G.E., and C.E. Keyser (comps). 2008 (revised October 2, 2019). Northeast (NE) Variant Overview - Forest Vegetation Simulator. Internal Rep. Fort Collins, CO: U. S. Department of Agriculture, Forest Service, Forest Management Service Center. 56p.

Dumais, D., C. Larouche, P. Raymond, S. Bédard, and M.C. Lambert. 2019. Survival and growth dynamics of red spruce seedlings planted under different forest cover densities and types. New Forests, 50(4), 573-592.

Dumais, D., and M. Prevost. 2016. Germination and establishment of natural red spruce (Picea rubens) seedlings in silvicultural gaps of different sizes. The Forestry Chronicle. 92(1): 90-100.

Dyer, M. E., and R.L. Bailey. 1987. A test of six methods for estimating true heights from stem analysis data. Forest Science. 33(1): 3-13.

Eagar, C., and M.B. Adams, editors. 1992. Ecology and decline of red spruce in the Eastern United States. Springer-Verlag. New York, N.Y.

Flegal, D.G. 1999. Soil survey of Pocahontas County, West Virginia. United States Department of Agriculture, Natural Resources Conservation Service, in cooperation with the West Virginia Agricultural and Forestry Experiment Station, Washington, DC.

Frank, R.M., and L.O. Safford. 1970. Lack of viable seed in the forest floor after clearcutting. Journal of Forestry. 68(12): 776-788.

Frank, R.M., and J.S. Bjorkbom. 1973. A silvicultural guide for spruce-fir in the Northeast. USDA Forest Service, General Technical Report NE-6. Northeastern Forest Experiment Station, Broomall, PA. 29 p.

Fraver, S., and A.S. White. 2005. Identifying growth releases in dendrochronological studies of forest disturbance. Canadian Journal of Forest Research. 35: 1648-1656.

Graves, H.S. 1906. Forest mensuration. John Wiley \& Sons, Inc., New York. 458 p.

Greenwood, M.S., C.L. O'Brien, J.D. Schatz, C.A. Diggins, M.E. Day, G.L. Jacobson, A.S. White, and R.G. Wagner. 2008. Is early life cycle success a determinant of the abundance of red spruce and balsam fir? Canadian Journal of Forest Research. 38: 2295-2305. 
Griffin, R.H., and J.E. Johnson. 1970. Polymorphic site index curves for spruce and balsam fir growing in even-aged stands in northern Maine. Bulletin, Maine Life Sciences and Agriculture Experiment Station, University of Maine. 765: 22 p.

Griffith, D.M., and R.H. Widmann. 2003. Forest Statistics for West Virginia: 1989 and 2000. USDA Forest Service Resource Bulletin NE-157, Newtown Square, PA.

Gordon, A.G. 1976. The taxonomy and genetics of Picea rubens and its relationship to Picea mariana. Canadian Journal of Botany. 54(9): 781-813.

Hamburg, S.P., and C.V. Cogbill. 1988. Historical decline of red spruce populations and climatic warming. Nature 331: 428-431.

Hart, A.C. 1965. Picea rubens Sarg. (Red Spruce). P. 250-259 in Silvics of North America, R.M. Burns, and B.H. Honkala (eds.). United States Department of Agriculture, Forest Service. Washington, D.C.

Hart, A.C., H.G. Abbott, and E.R. Ladd. 1968. Do small mammals and birds affect reproduction of spruce and fir? USDA Forest Service, Research Paper NE-110. Northeastern Forest Experiment Station, Broomall, PA. 8 p.

Hemery, G.E., P.S. Savill, and S.N. Pryor. 2005. Applications of the crown diameter-stem diameter relationship for different species of broadleaved trees. Forest ecology and management, 215(1-3), 285-294.

Hicks, R.R. Jr., and D.A. Mudrick. 1994. 1993 forest health: a status report for West Virginia. West Virginia Department of Agriculture, Charleston, WV. 68 p.

Hopkins, A.D. 1899. Report on investigations to determine the cause of unhealthy conditions of the spruce and pine from 1880-1893. Part I, the spruce investigation. West Virginia Agricultural Experiment Station, Bulletin 56:197-270.

Jacobson, G.L., T. Webb III, and E.C. Grimm. 1987. Patterns and rates of vegetation change during the deglaciation of eastern North America. P. 277-288 in North America and adjacent oceans during the last deglaciation. W.F. Ruddiman and H.E. Wright (eds.). Boulder, CO, Geological Society of America. The Geology of North America.

Jenkins, A.B. 2002. Organic carbon and fertility of forest soils on the Allegheny Plateau of West Virginia. M.Sc. Thesis, West Virginia University, Morgantown, West Virginia. JMP $^{\circledR}$, Version 14. SAS Institute Inc., Cary, NC, 1989-2019. 
Johnson, A.H., E.R. Cook, and T.G. Siccama. 1988. Climate and red spruce growth and decline in the northern Appalachians. Proceedings of the National Academy of Sciences of the United States of America 85(15): 5369-5373.

Kariuki, M. 2002. Height estimation in complete stem analysis using annual radial growth measurements. Forestry, 75(1), 63-74.

Korstian, C.F. 1937. Perpetuation of spruce on cut-over and burned lands in the higher southern Appalachian Mountains. Ecological Monographs 7(1): 126-167.

Larsen, D.R. 2017. Simple taper: Taper equations for the field forester. P. 265-278 In Proceedings of the 20th Central Hardwood Forest Conference, J.M. Kabrick, D.C. Dey, B.O. Knapp, D.R. Larsen, S.R. Shifley, H.E. Stelzer, (eds.). USDA, Forest Service, Columbia, MO.

LeBlanc, D.C., and D.J. Raynal. 1990. Red spruce decline on Whiteface Mountain, New York. II. Relationships between apical and radial growth decline. Canadian Journal of Forest Research, 20: 1415-1421.

Lenhart, D.J. 1972. An alternative procedure for improving height/age data from stem analysis. For. Sci. 18: 332.

Lewis, R.L. 1998. Transforming the Appalachian countryside: railroads, deforestation, and social change in West Virginia, 1880-1920. University of North Carolina, Chapel Hill.

Lorimer, C.G., and L.E. Frelich. 1989. A methodology for estimating canopy disturbance frequency and intensity in dense temperate forests. Canadian Journal Forest Research 19: 651-663.

Lutz, A. 2018. Characterizing red spruce (Picea rubens Sarg.) advanced reproduction in an high elevation stand in West Virginia. M.Sc. Thesis, West Virginia University, Morgantown, West Virginia.

Magnussen, S., and M. Penner. 1996. Recovering time trends in dominant height from stem analysis. Canadian Journal of Forest Research, 26(1): 9-22.

Mathias, J.M., and R.B. Thomas. 2018. Disentangling the effects of acidic air pollution, atmospheric $\mathrm{CO}_{2}$, and climate change on recent growth of red spruce trees in the Central Appalachian Mountains. Global Change Biology, 24: 3938-3953. 
Mayfield, A.E., and J.R. Hicks. 2010. Abundance of red spruce regeneration across sprucehardwood ecotones at Gaudineer Knob, West Virginia. P. 113-125 In Ecology and Management of High Elevation Forests in the Central and Southern Appalachian Mountains, J. S. Rentch, \& T. M. Schuler (eds.). U.S. Department of Agriculture, Forest Service, Northern Research Station.

McLaughlin, S.B., D.J. Downing, T.J. Blasing, E.R. Cook, and H.S. Adams. 1987. An analysis of climate and competition as contributors to decline of red spruce in high elevation Appalachian forests of the eastern United States. Oecologia 72(4), 487-501.

McLintock, T.F., and C.A. Bickford. 1957. A proposed site index for red spruce in the Northeast. Station Paper NE-93. Upper Darby, PA: US Department of Agriculture, Forest Service, Northeastern Forest Experiment Station. 30 p. 93.

Mech, L.D. 2006. Age-related body mass and reproductive measurements of gray wolves in Minnesota. Journal of Mammalogy, 87(1), 80-84.

Mielke, M.E., D.C. Soctomah, M.A. Marsden, and W.M. Ciesla. 1986. Decline and mortality of red spruce in West Virginia. USDA Forest Service Report 86-4. Newtown Square, PA: U.S. Department of Agriculture, Forest Service, Northern Research Station.

Mlodziansky, A.K. 1898. Measuring the forest crop. USDA Division of Forestry Bulletin 20: $71 \mathrm{p}$.

Moore, R. 2011. Revised 2006 Environmental impact statement for the Monongahela National Forest, forest plan revision. USDA Forest Service, Elkins, West Virginia.

National Climatic Data Center. 2020. Monthly summaries, Pocahontas, Randolph, Tucker Counties, WV. Accessed 21 July 2020. Available online at www.ncdc.noaa.gov/cdo-web.

Nesbitt, S.A., M.G. Spalding, K.L. Candelora, P.S. Kubilis, and S.T. Schwikert. 2008. Body mass index (BMI) of normal sandhill cranes. P. 133-137 in Proceedings of the Tenth North American Crane Workshop, M.J. Folk and S.A. Nesbitt (eds.). Zacatecas City, Zacatecas, Mexico: North American Crane Working Group.

Newberry, J.D. 1978. Dominant height growth models and site index curves for site-prepared slash pine plantations in the lower Coastal Plain of Georgia and North Florida. M.Sc. thesis, University of Georgia. $47 \mathrm{p}$.

Nowacki, G.J., and M.D. Abrams. 1997. Radial-growth averaging criteria for reconstructing disturbance histories from presettlement-origin oaks. Ecological Monograph 67: 225249. 
Nowacki, G., R. Carr, and M. Van Dyck. 2010. The current status of red spruce in the Eastern United States: Distribution, population trends, and environmental drivers. Ecology and Management of High-Elevation Forests in the Central and Southern Appalachian Mountains. General Technical Report NRS-P-64. Slatyfork, WV: USDA, Forest Service, Northern Research Station. 140-162 p.

Pauley, E.F. 1989. Stand composition and structure of a second-growth red spruce forest in West Virginia. Castanea 54(1): 12-18.

Price, P.H. 1968. Geologic map of West Virginia. WV Geologic and Economic Survey.

Stephenson, S.L., and J.F. Clovis, 1983. Spruce forests of the Allegheny Mountains in central West Virginia. Castanea 48(1); 1-12.

PRISM Climate Group. Oregon State University. 30 Year Normals. Accessed 20 July 2020. Available online at http://prism.oregonstate.edu, created October 2019.

R Core Team (2013). R: A language and environment for statistical computing. R Foundation for Statistical Computing, Vienna, Austria. URL http://www.R-project.org/.

Randall, A.G. 1974. Seed dispersal into two spruce-fir clearcuts in eastern Maine. University of Maine Life Sciences and Agriculture Experiment Station, Research in the Life Sciences 21(8): 15.

Rentch, J.S., W.M. Ford, T.M. Schuler, J. Palmer, and C.A. Diggins. 2016. Release of suppressed red spruce using canopy gap creation- ecological restoration in the central Appalachians. Natural Areas Journal, (36):29-37

Rentch, J.S., T.M. Schuler, W.M. Ford, and G.J. Nowacki. 2007. Red Spruce stand dynamics, simulations, and restoration opportunities in the central Appalachians. Restoration Ecology, 15(3): 440-452.

Rentch, J.S., T.M. Schuler, G.J. Nowacki, N.R. Beane, and M.W. Ford. 2010. Canopy gap dynamics of second-growth red spruce-northern hardwood stands in West Virginia. Forest Ecology and Management, 260: 1921-1929.

Rollins, A.W. 2005. Analysis of red spruce (Picea rubens) regeneration in Pocahontas, Randolph, and Tucker counties, West Virginia. M.Sc. Thesis, West Virginia University, Morgantown, West Virginia. 
Saunders, Paul Richard. 1979. The vegetational impact of human disturbance on the spruce-fir forests of the southern Appalachian Mountains. PhD dissertation, Durham, NC: Duke University. $188 \mathrm{p}$.

Schuler, T.M., W.M. Ford, and R.J. Collins. 2002. Successional dynamics and restoration implications of a montane coniferous forest in the central Appalachians, USA. Natural Areas Journal, 88-98.

Sendak, P.E., J.C. Brissette, and R.M. Frank. 2003. Silviculture affects composition, growth, and yield in mixed northern conifers: 40-year results from the Penobscot Experimental Forest. Canadian Journal of Forest Research, 33: 2116-2128.

Seymour, R.S., and M.A. Fajvan. 2001. Influence of prior growth suppression and soil on red spruce site index. Northern Journal of Applied Forestry, 18(2), 55-62.

Shallenberger, S.W., K.L. Carvell, C. Smith. 1986. Crown/stem diameter relationship of four Appalachian hardwoods. West Virginia Forestry Notes No. 12, pp. 4-6.

Stasinopoulos, D.M., R.A. Rigby. 2007. Generalized additive models for location scale and shape (GAMLSS) in R. Journal of Statistical Software, 23(7): 1-46.

Stokes, M.A., and Smiley, T.L. 1968. An introduction to tree-ring dating. University of Chicago Press, Chicago, Illinois.

Strausbaugh, P.D., and E.L. Core. 1952. Flora of West Virginia (Part 1). West Virginia University Bulletin, 273.

Thomas-Van Gundy, M.A. and M.P. Strager. 2012. European settlement-era vegetation of the Monongahela National Forest, West Virginia. Gen. Tech. Rep. NRS-GTR-101. Newtown Square, PA: U.S. Department of Agriculture, Forest Service, Northern Research Station. $39 \mathrm{p}$.

Thomas-Van Gundy, M.A., and B.M. Sturtevant. 2014. Using scenario modeling for red spruce. Journal of Forestry, 112(5): 457-466.

Ulijaszek, S.J., F.E. Johnston, and M.A. Preece. 1998. The Cambridge encyclopedia of human growth and development. Cambridge University Press, Cambridge, U.K.

US Climate Data. 2020. Monthly Averages Pickens, WV. Accessed 7 July 2020. Available online at www.usclimatedata.com. 
Vickers, L.A., D.R. Larsen, B.O. Knapp, J.M. Kabrick, and D.C. Dey. 2017. Reference charts for young stands - a quantitative methodology for assessing tree performance. Canadian Journal of Forest Research, 47(12): 1677-1686.

Walter, L.C. 1967. Silviculture of the minor southern conifers. Stephen F. Austin State College School of Forestry, Bulletin 15. Nacogdoches, TX. 56-62 p.

Watts, W.A. 1979. Late quaternary vegetation of central Appalachia and the New Jersey coastal plain. Ecological Monographs 49(4): 427-469.

West Virginia Division of Forestry (WVDOF). 2002. Management Plan for Kumbrabow State Forest. p 2.

West Virginia GIS Technical Center. 2013. Red Spruce (Picea rubens) Cover In West Virginia. Accessed 20 July 2020. Available Online at https://wvgis.wvu.edu.

Westfall, J.A., and C.T. Scott. 2010. Taper models for commercial tree species in the Northeastern United States. Forest Science, 56(6), 515-528.

Winkler, C., K. Linden, A. Mayr, T. Schultz, T. Welchowski, J. Breuer, and U. Herberg. 2019. RefCurv: A Software for the Construction of Pediatric Reference Curves.

Wu, X., F.J. McCormick, and R.T. Busing. 1999. Growth pattern of Picea rubens prior to canopy recruitment. Plant Ecology, 140: 245-253.

Yamaguchi, D.K. 1991. A simple method for cross-dating increment cores from living trees. Canadian Journal of Forest Research. 21: 414-416.

Yang, Y., S. Huang, and S.X. Meng. 2009. Development of a tree-specific stem profile model for white spruce: a nonlinear mixed model approach with a generalized covariance structure. Forestry, 82(5), 541-555.

Yetter, E.L. 2020. Dendroclimatic Analysis and Site Index Modeling of Central Appalachian Red Spruce. M.Sc. Thesis, West Virginia University, Morgantown, West Virginia.

Youngblood, A., and L.O. Safford. 2008. Picea A. Dietr. Spruce. P. 793 in Seeds of woody plants in the United States. C. S. Schopmeyer, tech. coord. U.S. Department of Agriculture, Agriculture Handbook 727. Washington, DC.

Zenner, E.K., D.J. Heggenstaller, P.H. Brose, J.E. Peck, and K.C. Steiner. 2012. Reconstructing the competitive dynamics of mixed-oak neighborhoods. Canadian Journal of Forest Research, 42(9), 1714-1723. 


\section{APPENDICES}

Appendix 1: The lambda, sigma, and mu values for the centiles modelled for height class one where " $\mathrm{x}$ " is age in years and " $\mathrm{P}$ " is percentile.

Height Class 1

\begin{tabular}{|c|c|c|c|c|c|c|c|c|c|c|}
\hline$x$ & mu & gma & nu & P3 & P10 & P25 & P50 & P75 & P90 & P97 \\
\hline 00 & & & & 007 & & & 018 & .028 & 044 & .076 \\
\hline & & & & & & & & & & \\
\hline & & & & & & & & & & \\
\hline .515 & 074 & & & 30 & & & & & & \\
\hline 2.020 & .092 & & & 7 & 048 & & & & & \\
\hline & & & & & & & & & & \\
\hline & & & & & & & & & & \\
\hline & & & & & & & & & & \\
\hline & & & & & & & & & & \\
\hline & & & & & & & & & & \\
\hline 5.051 & & & & & & & & & & \\
\hline & & & & & & & & & & \\
\hline 061 & 241 & & & c & & & & & & \\
\hline & & & & & & & & & & \\
\hline & & & & & & & & & & \\
\hline & & & & & & & & & & \\
\hline & & & & & & & & & & \\
\hline & & & & & & & & & & \\
\hline & & & & & & & & & & \\
\hline 596 & & & & & & & & & & \\
\hline & & & & & & & & & & \\
\hline & & & & & & & & & & \\
\hline & & & & & & & & & & \\
\hline 11.616 & & & & & & & & & & \\
\hline & & & & & & & & & & \\
\hline & & & & & & & & & & \\
\hline & & & & & & & & & & \\
\hline & & & & & & & & & & \\
\hline & & & & & & & & & & \\
\hline 14.646 & 0.58 & & & & & & & & & \\
\hline & 0.604 & & & 0.247 & 0.327 & 0.436 & 604 & 0.840 & & \\
\hline & 0.625 & & & & & & & & & \\
\hline & & & & & & & & & & \\
\hline & & & & & & & & 0.921 & 1.233 & 1.647 \\
\hline $1 / .1 / 2$ & 0.000 & $0.4 / 4$ & -0.005 & 0.283 & 0.375 & 0.500 & 0.688 & 0.948 & 1.265 & 1.682 \\
\hline
\end{tabular}




\begin{tabular}{|c|c|c|c|c|c|c|c|c|c|c|}
\hline & & & & & & & & & & \\
\hline .182 & 730 & 0.468 & 017 & 0.300 & 0.399 & 0.532 & 0.730 & 1.000 & 1.326 & 750 \\
\hline & 751 & 466 & 028 & 309 & & & 751 & 026 & 357 & 783 \\
\hline & & & & & & & 771 & & & \\
\hline 7 & 792 & 460 & & 27 & & & 792 & 77 & & \\
\hline .202 & 812 & .457 & 062 & 335 & 447 & 94 & 812 & 102 & 144 & 87 \\
\hline 7 & & & & & & & & & & \\
\hline & & & & & & & & & & ב \\
\hline 17 & & I & & & & & & & & \\
\hline 22 & & & & & & & & & & \\
\hline & & & & & & & & & & \\
\hline 3.232 & 928 & .441 & & 386 & & & & & & \\
\hline 3.737 & 0.946 & 0.439 & 139 & 0.394 & 0.527 & 0.699 & 0.946 & .264 & .625 & 066 \\
\hline 1.242 & 964 & 0.436 & 150 & .402 & .538 & 0.713 & .964 & 285 & 648 & U४ \\
\hline .747 & 982 & 0.434 & 61 & 409 & 48 & & 982 & 06 & 71 & 111 \\
\hline & 999 & 31 & & 17 & & & & & & 133 \\
\hline & & 28 & & & & & & & & \\
\hline 63 & & $4<0$ & & & & & & & & \\
\hline & & & & & & & & & & \\
\hline & & & & & & & & & & \\
\hline 7.778 & 080 & .418 & & .454 & & & & & & 22 \\
\hline 3.283 & 095 & 0.416 & 239 & 0.461 & 0.619 & 0.819 & 995 & & .808 & 24 \\
\hline .788 & 109 & .413 & 250 & 467 & & & 09 & & 824 & 25 \\
\hline .293 & & 1 & & & & & & & & 272 \\
\hline 9.798 & 138 & 0.408 & & & & 54 & & & & 283 \\
\hline 30.303 & 151 & 0.406 & & & & & & & & 298 \\
\hline & & & & & & & & & & \\
\hline & & & & & & & & & & 321 \\
\hline & & & & & & & & & & \\
\hline & & & & & & & & & & $3 \Delta$ \\
\hline .828 & 213 & .394 & 339 & & & & & 565 & 34 & .35 \\
\hline 3.333 & .225 & 392 & 350 & 523 & 05 & .928 & 225 & 1.577 & .945 & 35 \\
\hline 33.838 & .236 & 389 & 361 & & 713 & & 236 & 1.588 & 56 & 367 \\
\hline 34.343 & 247 & 0.387 & 72 & & 0.720 & & 247 & & 66 & 375 \\
\hline .048 & .257 & 0.385 & .383 & & & & & & & 38 \\
\hline & 267 & & & & & & & & & 30 \\
\hline & & & & & & & & & & \\
\hline & & & & & & & & & & \\
\hline & 1.297 & & & & & & & & & 2.40 \\
\hline & 1.306 & & & & & & & & & $2.4 C$ \\
\hline 7870 & 1.315 & 0.371 & 0.449 & 0.569 & 0.770 & 1.008 & 1.315 & 1.667 & 2.024 & 2.4 \\
\hline
\end{tabular}




\begin{tabular}{lllllllllll}
38.384 & 1.324 & 0.369 & 0.460 & 0.574 & 0.777 & 1.016 & 1.324 & 1.676 & 2.031 & 2.418 \\
38.889 & 1.332 & 0.367 & 0.471 & 0.578 & 0.783 & 1.024 & 1.332 & 1.684 & 2.037 & 2.422 \\
39.394 & 1.341 & 0.365 & 0.482 & 0.583 & 0.790 & 1.032 & 1.341 & 1.692 & 2.044 & 2.425 \\
39.899 & 1.349 & 0.363 & 0.494 & 0.588 & 0.796 & 1.040 & 1.349 & 1.700 & 2.050 & 2.429 \\
40.404 & 1.358 & 0.360 & 0.505 & 0.592 & 0.802 & 1.047 & 1.358 & 1.707 & 2.056 & 2.432 \\
40.909 & 1.366 & 0.358 & 0.516 & 0.597 & 0.809 & 1.055 & 1.366 & 1.715 & 2.062 & 2.435 \\
41.414 & 1.374 & 0.356 & 0.527 & 0.601 & 0.815 & 1.062 & 1.374 & 1.722 & 2.068 & 2.438 \\
41.919 & 1.381 & 0.354 & 0.538 & 0.606 & 0.821 & 1.070 & 1.381 & 1.729 & 2.073 & 2.440 \\
42.424 & 1.389 & 0.352 & 0.549 & 0.610 & 0.827 & 1.077 & 1.389 & 1.736 & 2.078 & 2.443 \\
42.929 & 1.397 & 0.350 & 0.560 & 0.615 & 0.833 & 1.084 & 1.397 & 1.743 & 2.083 & 2.445 \\
43.434 & 1.404 & 0.348 & 0.571 & 0.619 & 0.840 & 1.092 & 1.404 & 1.750 & 2.089 & 2.448 \\
43.939 & 1.412 & 0.346 & 0.582 & 0.624 & 0.846 & 1.099 & 1.412 & 1.757 & 2.093 & 2.450 \\
44.444 & 1.419 & 0.344 & 0.593 & 0.628 & 0.852 & 1.106 & 1.419 & 1.763 & 2.098 & 2.452 \\
44.949 & 1.426 & 0.342 & 0.604 & 0.633 & 0.858 & 1.113 & 1.426 & 1.770 & 2.103 & 2.454 \\
45.455 & 1.433 & 0.340 & 0.615 & 0.637 & 0.864 & 1.120 & 1.434 & 1.776 & 2.108 & 2.456 \\
45.960 & 1.441 & 0.338 & 0.626 & 0.641 & 0.870 & 1.127 & 1.441 & 1.782 & 2.113 & 2.459 \\
46.465 & 1.448 & 0.336 & 0.637 & 0.646 & 0.876 & 1.134 & 1.448 & 1.789 & 2.117 & 2.461 \\
46.970 & 1.455 & 0.334 & 0.649 & 0.650 & 0.882 & 1.141 & 1.455 & 1.795 & 2.122 & 2.463 \\
47.475 & 1.462 & 0.332 & 0.660 & 0.655 & 0.888 & 1.148 & 1.462 & 1.801 & 2.126 & 2.465 \\
47.980 & 1.469 & 0.330 & 0.671 & 0.659 & 0.894 & 1.155 & 1.469 & 1.807 & 2.131 & 2.467 \\
48.485 & 1.476 & 0.328 & 0.682 & 0.664 & 0.900 & 1.162 & 1.476 & 1.814 & 2.135 & 2.469 \\
48.990 & 1.483 & 0.326 & 0.693 & 0.668 & 0.906 & 1.169 & 1.483 & 1.820 & 2.140 & 2.471 \\
49.495 & 1.490 & 0.324 & 0.704 & 0.673 & 0.912 & 1.176 & 1.490 & 1.826 & 2.145 & 2.474 \\
50.000 & 1.497 & 0.322 & 0.715 & 0.678 & 0.919 & 1.183 & 1.497 & 1.832 & 2.149 & 2.476 \\
\hline
\end{tabular}

Appendix 2: The lambda, sigma, and mu values for the centiles modelled for height class two where " $\mathrm{x}$ " is age in years and " $\mathrm{P}$ " is percentile.

Height Class 2

\begin{tabular}{lllllllllll}
\hline $\mathbf{x}$ & $\mathbf{m u}$ & sigma & nu & P3 & P10 & P25 & P50 & P75 & P90 & P97 \\
\hline 0.000 & 0.022 & 0.515 & -0.623 & 0.010 & 0.013 & 0.016 & 0.022 & 0.033 & 0.052 & 0.096 \\
0.768 & 0.056 & 0.519 & -0.578 & 0.026 & 0.032 & 0.041 & 0.056 & 0.083 & 0.130 & 0.234 \\
1.535 & 0.091 & 0.523 & -0.533 & 0.041 & 0.051 & 0.066 & 0.091 & 0.134 & 0.207 & 0.363 \\
2.303 & 0.126 & 0.527 & -0.487 & 0.056 & 0.070 & 0.090 & 0.126 & 0.185 & 0.285 & 0.485 \\
3.071 & 0.161 & 0.531 & -0.442 & 0.071 & 0.089 & 0.116 & 0.161 & 0.238 & 0.362 & 0.602 \\
3.838 & 0.198 & 0.535 & -0.397 & 0.085 & 0.108 & 0.142 & 0.198 & 0.293 & 0.441 & 0.716 \\
4.606 & 0.236 & 0.539 & -0.352 & 0.099 & 0.127 & 0.168 & 0.236 & 0.349 & 0.522 & 0.828 \\
5.374 & 0.277 & 0.543 & -0.307 & 0.114 & 0.147 & 0.195 & 0.277 & 0.408 & 0.605 & 0.942 \\
6.141 & 0.319 & 0.547 & -0.261 & 0.128 & 0.167 & 0.224 & 0.319 & 0.470 & 0.691 & 1.057 \\
6.909 & 0.364 & 0.551 & -0.216 & 0.143 & 0.188 & 0.254 & 0.364 & 0.536 & 0.782 & 1.175 \\
7.677 & 0.411 & 0.555 & -0.171 & 0.158 & 0.210 & 0.286 & 0.411 & 0.605 & 0.877 & 1.297
\end{tabular}




\begin{tabular}{|c|c|c|c|c|c|c|c|c|c|c|}
\hline 444 & .462 & & & & & & & & & \\
\hline 9.212 & 0.516 & & & & & & & & & \\
\hline 9.980 & & & & & & & & & & \\
\hline & & & & & & & & 925 & 99 & 816 \\
\hline & & & & & & & & & 13 & 950 \\
\hline & .762 & & & .249 & & .518 & & & 529 & .083 \\
\hline .051 & .831 & .560 & .145 & 0.265 & .389 & .563 & .831 & 200 & 645 & .215 \\
\hline .818 & .902 & 557 & 190 & .281 & & & & & 761 & .344 \\
\hline 586 & 6 & & & & & & & & & .405 \\
\hline & & & & & & & & & & טבניט \\
\hline & & & & & & & & & & 705 \\
\hline & & & & & & & & & & .815 \\
\hline 7 & 1.284 & & & & & & & & & .919 \\
\hline 8.424 & 1.363 & 0.510 & 0.461 & 0.384 & 0.626 & 0.937 & 1.363 & 876 & 414 & 3.018 \\
\hline .192 & .442 & 499 & 507 & .403 & 0.666 & .997 & & 68 & 511 & 3.110 \\
\hline .960 & .522 & .488 & 552 & .425 & 707 & 59 & & 58 & 503 & 3.196 \\
\hline .727 & .600 & 75 & 97 & & & & & & 991 & 3.276 \\
\hline & . $6 / 8$ & & & & & & & & & 3.352 \\
\hline 200 & 1.755 & & & & & & & & & 3.423 \\
\hline .030 & & & & & & & & & & \\
\hline & 1.906 & & & & & & & & & .551 \\
\hline 4.566 & 1.979 & 413 & 823 & & & & & & & 3.610 \\
\hline .333 & 2.050 & .402 & 868 & 0.621 & & & & & & 3.666 \\
\hline .101 & 2.120 & & & & & & & & & 3.719 \\
\hline .869 & 188 & & & 0.690 & & & & & & 3.769 \\
\hline .636 & .253 & 69 & & 25 & 00 & & & & 20 & 3.818 \\
\hline .404 & 2.316 & & & & & & & & & 3.864 \\
\hline & & & & & & & & & & 908 \\
\hline & & & & & & & & & & \\
\hline & & & & & & & & & & בכב.נת \\
\hline & & & & & & & & & & 4.032 \\
\hline .242 & 2.597 & 322 & & 0.924 & 1.483 & 2.030 & & & 521 & 4.070 \\
\hline 3.010 & 2.646 & 316 & 320 & 0.953 & 1.523 & 2.077 & & 3.198 & 3.664 & 4.106 \\
\hline 3.778 & 2.692 & 311 & 365 & 0.980 & 1.562 & & & 3.243 & 705 & 4.141 \\
\hline 1.545 & & & & & & & & & & 4.174 \\
\hline .313 & .711 & .302 & & & & & & & & 4.206 \\
\hline & 2.815 & & & & & & & & & 4.236 \\
\hline & 2.851 & & & & & & & & & 4.264 \\
\hline & 2.885 & & & & & & & & & .290 \\
\hline & 2.916 & & & & & & & & & 4.315 \\
\hline & 2.945 & 0.289 & 1.681 & 1.121 & 1.767 & 2.371 & 2.966 & 3.498 & 3.935 & 4.338 \\
\hline
\end{tabular}




\begin{tabular}{|c|c|c|c|c|c|c|c|c|c|c|}
\hline & & & & & & & & & & \\
\hline 687 & .996 & 0.286 & 771 & 1.148 & 1.808 & 2.423 & 3.022 & 3.552 & 3.984 & 380 \\
\hline & 18 & 285 & 817 & & 826 & 2.446 & 3.047 & & 006 & 398 \\
\hline & & & 362 & & & .467 & 70 & & 26 & 414 \\
\hline 90 & 056 & 85 & 907 & & 858 & 487 & 092 & & 44 & 429 \\
\hline .758 & 072 & 285 & 952 & 195 & 872 & .505 & 112 & 638 & 061 & 442 \\
\hline & 37 & & & 5 & & & & & & \\
\hline & & & & & & & & & & 70 \\
\hline 61 & & & & & .909 & & & & & \\
\hline & & & & & & & & & & \\
\hline & & & & & & & & & & 190 \\
\hline 8.364 & 135 & 290 & 223 & 253 & 940 & 2.589 & .203 & & & 497 \\
\hline 9.131 & .141 & 0.292 & .268 & 1.262 & .949 & 2.600 & 3.215 & 3.735 & 4.143 & .504 \\
\hline 9.899 & 147 & .294 & 314 & 272 & 958 & 2.611 & .227 & 3.746 & & 51 \\
\hline .667 & 151 & 296 & 359 & 282 & .967 & 621 & 39 & & 162 & 518 \\
\hline .434 & & & 404 & 92 & 77 & & & & & 52 \\
\hline & & & & & & & & & & נת \\
\hline & & & & & 996 & & & & & \\
\hline & & & & & & & & & & \\
\hline & 168 & & & & & & & & & \\
\hline 5.273 & 170 & 318 & 630 & 48 & .028 & & & & & 570 \\
\hline 5.040 & 172 & 0.322 & 675 & .361 & .040 & 2.700 & 3.325 & & & 581 \\
\hline .808 & 174 & 327 & 720 & 75 & .052 & & & & & 5 \\
\hline & & & 65 & & & & & & & 2 \\
\hline & & & & & & & & & 274 & 01 \\
\hline .111 & 179 & 13 & 856 & & .092 & .753 & & & .287 & \\
\hline & & & & & & & & & & \\
\hline & & & & & & & & & & \\
\hline & & & & & & & & & & \\
\hline & 184 & & & & & & & & & 67 \\
\hline 2.949 & 184 & 375 & 082 & .500 & .168 & 2.826 & & & & 58 \\
\hline 3.717 & 185 & 381 & 127 & 518 & 2.185 & 2.841 & 3.467 & 78 & 4.363 & 592 \\
\hline 64.485 & .185 & 388 & 172 & 535 & 2.201 & 2.857 & 3.482 & & 376 & 3 \\
\hline 65.253 & 3.186 & 396 & 217 & & 218 & 2.873 & & & 389 & \\
\hline 6.020 & .186 & 0.403 & 262 & & 2.236 & 889 & & & & \\
\hline 5.788 & 187 & & 307 & & 2.253 & 2.905 & & & & \\
\hline & & & & & & & & & & \\
\hline & & & & & & & & & & \\
\hline 69.091 & & & & & & & & & & \\
\hline & 3.188 & 0.443 & & & & & & & & \\
\hline 0.626 & 180 & 0.451 & 3.533 & .685 & 2.343 & 2.988 & 3.603 & 4.103 & 4.475 & 4 \\
\hline
\end{tabular}




\begin{tabular}{lllllllllll}
71.394 & 3.189 & 0.460 & 3.579 & 1.705 & 2.362 & 3.005 & 3.619 & 4.117 & 4.487 & 4.800 \\
72.162 & 3.189 & 0.469 & 3.624 & 1.724 & 2.381 & 3.023 & 3.634 & 4.131 & 4.500 & 4.811 \\
72.929 & 3.190 & 0.478 & 3.669 & 1.744 & 2.400 & 3.040 & 3.650 & 4.145 & 4.512 & 4.821 \\
73.697 & 3.190 & 0.488 & 3.714 & 1.764 & 2.419 & 3.057 & 3.665 & 4.159 & 4.524 & 4.832 \\
74.465 & 3.191 & 0.497 & 3.759 & 1.784 & 2.438 & 3.075 & 3.681 & 4.173 & 4.537 & 4.843 \\
75.232 & 3.192 & 0.507 & 3.804 & 1.804 & 2.457 & 3.092 & 3.697 & 4.186 & 4.549 & 4.853 \\
76.000 & 3.192 & 0.517 & 3.850 & 1.824 & 2.476 & 3.110 & 3.712 & 4.200 & 4.561 & 4.864 \\
\hline
\end{tabular}

Appendix 3: The lambda, sigma, and mu values for the centiles modelled for height class three where " $\mathrm{x}$ " is age in years and " $\mathrm{P}$ " is percentile.

Height Class 3

\begin{tabular}{|c|c|c|c|c|c|c|c|c|c|c|}
\hline$x$ & $\mathrm{mu}$ & sigma & nu & P3 & P10 & P25 & P50 & P75 & P90 & P97 \\
\hline 0.000 & 0.021 & 0.654 & -0.028 & 0.006 & 0.009 & 0.014 & 0.021 & 0.033 & 0.049 & 0.074 \\
\hline 1.030 & 0.106 & 0.650 & -0.012 & 0.032 & 0.046 & 0.069 & 0.106 & 0.165 & 0.245 & 0.364 \\
\hline 2.061 & 0.191 & 0.647 & 0.005 & 0.056 & 0.083 & 0.123 & 0.191 & 0.295 & 0.437 & 0.643 \\
\hline 3.091 & 0.276 & 0.643 & 0.021 & 0.081 & 0.120 & 0.179 & 0.276 & 0.425 & 0.625 & 0.911 \\
\hline 4.121 & 0.361 & 0.639 & 0.037 & 0.106 & 0.157 & 0.234 & 0.361 & 0.554 & 0.809 & 1.170 \\
\hline 5.152 & 0.446 & 0.635 & 0.054 & 0.130 & 0.194 & 0.289 & 0.446 & 0.681 & 0.989 & 1.419 \\
\hline 6.182 & 0.531 & 0.631 & 0.070 & 0.154 & 0.231 & 0.345 & 0.531 & 0.808 & 1.166 & 1.660 \\
\hline 7.212 & 0.616 & 0.627 & 0.086 & 0.178 & 0.268 & 0.400 & 0.616 & 0.933 & 1.339 & 1.893 \\
\hline 8.242 & 0.701 & 0.623 & 0.102 & 0.201 & 0.305 & 0.456 & 0.701 & 1.057 & 1.509 & 2.118 \\
\hline 9.273 & 0.786 & 0.619 & 0.119 & 0.225 & 0.342 & 0.512 & 0.786 & 1.181 & 1.676 & 2.337 \\
\hline 10.303 & 0.871 & 0.614 & 0.135 & 0.248 & 0.379 & 0.568 & 0.871 & 1.303 & 1.840 & 2.549 \\
\hline 11.333 & 0.956 & 0.610 & 0.151 & 0.271 & 0.416 & 0.625 & 0.956 & 1.425 & 2.002 & 2.755 \\
\hline 12.364 & 1.041 & 0.607 & 0.168 & 0.293 & 0.452 & 0.681 & 1.041 & 1.546 & 2.161 & 2.956 \\
\hline 13.394 & 1.126 & 0.603 & 0.184 & 0.315 & 0.489 & 0.738 & 1.126 & 1.666 & 2.319 & 3.153 \\
\hline 14.424 & 1.211 & 0.600 & 0.200 & 0.337 & 0.526 & 0.794 & 1.211 & 1.786 & 2.474 & 3.347 \\
\hline 15.455 & & & & & & & 1.296 & & 2.629 & 3.538 \\
\hline 16.485 & 1.381 & 0.594 & 0.233 & 0.379 & 0.597 & 0.907 & 1.381 & 2.025 & 2.782 & 3.726 \\
\hline 17.515 & 1.466 & 0.591 & 0.249 & 0.398 & 0.633 & 0.963 & 1.466 & 2.144 & 2.934 & 3.911 \\
\hline 18.545 & 1.551 & 0.589 & 0.266 & 0.418 & 0.668 & 1.019 & 1.551 & 2.262 & 3.085 & 4.095 \\
\hline 19.576 & 1.636 & 0.587 & 0.282 & 0.436 & 0.702 & 1.075 & 1.636 & 2.380 & 3.235 & 4.276 \\
\hline 20.606 & 1.720 & 0.585 & 0.298 & 0.454 & 0.737 & 1.131 & 1.720 & 2.498 & 3.384 & 4.455 \\
\hline 21.636 & 1.805 & 0.583 & 0.315 & 0.471 & 0.770 & 1.187 & 1.805 & 2.616 & 3.532 & 4.631 \\
\hline 22.667 & 1.890 & 0.581 & 0.331 & 0.487 & 0.804 & 1.242 & 1.890 & 2.733 & 3.678 & 4.804 \\
\hline 23.697 & 1.975 & 0.579 & 0.347 & 0.503 & 0.838 & 1.299 & 1.975 & 2.849 & 3.822 & 4.974 \\
\hline 24.727 & 2.060 & 0.576 & 0.363 & 0.519 & 0.872 & 1.355 & 2.060 & 2.964 & 3.964 & 5.140 \\
\hline 25.758 & 2.145 & 0.574 & 0.380 & 0.535 & 0.906 & 1.412 & 2.145 & 3.078 & 4.103 & 5.300 \\
\hline 26.788 & 2.230 & 0.571 & 0.396 & 0.551 & 0.940 & 1.469 & 2.230 & 3.191 & 4.239 & 5.455 \\
\hline 27.818 & 2.315 & 0.567 & 0.412 & 0.568 & 0.976 & 1.527 & 2.315 & 3.303 & 4.372 & 5.604 \\
\hline
\end{tabular}




\begin{tabular}{|c|c|c|c|c|c|c|c|c|c|c|}
\hline & 400 & & & & & & & & & \\
\hline & .485 & & & & & & & & & \\
\hline & 570 & & & & & & & & & \\
\hline & & & & & & & & & & \\
\hline & & & & & & & & & & 237 \\
\hline & 825 & & & & .223 & .901 & & & & 335 \\
\hline .030 & 910 & 524 & .527 & 0.728 & .272 & .969 & 2.910 & .023 & 170 & .434 \\
\hline & 95 & & 3 & 0.7 & 4 & & & & & 20 \\
\hline & 30 & & & & & & & & & 600 \\
\hline & 165 & & & & & & & & & \\
\hline & 250 & & & & & & & & & \\
\hline & & & & & & & & & & \\
\hline & .420 & & & .976 & 1.631 & & & & & \\
\hline 42 & .505 & & 0.641 & 1.030 & 1.701 & 2.497 & 3.505 & 4.631 & 727 & 900 \\
\hline & 590 & & 657 & .088 & .774 & 580 & & & 804 & 5 \\
\hline & 675 & & 673 & 149 & .849 & 663 & & & 69 & 005 \\
\hline & 760 & & & & 1.927 & & & & & .04 \\
\hline & 845 & & & & 2.007 & & & & & .091 \\
\hline & 930 & & & & & & & & & \\
\hline & 015 & & & & & & & & & \\
\hline & 100 & & & & & & & & & \\
\hline & .184 & & 0.771 & & 2.347 & & & & & 5 \\
\hline & 269 & & 0.788 & 1.664 & 2.436 & & & & & 9 \\
\hline & 354 & & & & & & & & & 334 \\
\hline & 439 & & & & & & & & & 375 \\
\hline & 524 & & & & 2.710 & & & & & $41 \epsilon$ \\
\hline & 609 & & & & 2.803 & & & & & \\
\hline & 694 & & & & & & & & & \\
\hline & .779 & & & & & & & & & \\
\hline & & & & & & & & & & \\
\hline & 949 & & & & & & & & & .63 \\
\hline & .034 & & 0.934 & 2.479 & 3.279 & & & & & .68 \\
\hline & .119 & 268 & 0.951 & 2.575 & 3.376 & & & & & .73 \\
\hline & 5.204 & 1 & 967 & 2.672 & 3.472 & 4.290 & 5.204 & 6.124 & & .780 \\
\hline & & & & & & & & & & .83 \\
\hline & $.3 / 4$ & & & & & & & & & .88 \\
\hline & .459 & & & & & & & & & 93 \\
\hline & & & & & & & & & & .99 \\
\hline & & & & & & & & & & \\
\hline & & & & & & & & & & .10 \\
\hline & .799 & & 1.081 & 3.355 & 4.145 & 4.934 & 5.799 & 6.653 & 7.414 & \\
\hline
\end{tabular}




\begin{tabular}{|c|c|c|c|c|c|c|c|c|c|c|}
\hline 71.091 & 5.884 & 0.215 & 1.098 & 3.452 & 4.241 & 5.026 & 5.884 & 6.730 & 7.483 & 8.219 \\
\hline 72.121 & 5.969 & 0.210 & 1.114 & 3.549 & 4.336 & 5.117 & 5.969 & 6.807 & 7.552 & 8.279 \\
\hline 73.152 & 6.054 & 0.205 & 1.130 & 3.645 & 4.430 & 5.207 & 6.054 & 6.885 & 7.622 & 8.340 \\
\hline 74.182 & 6.139 & 0.201 & 1.147 & 3.741 & 4.524 & 5.298 & 6.139 & 6.963 & 7.693 & 8.403 \\
\hline 75.212 & 6.224 & 0.197 & 1.163 & 3.836 & 4.618 & 5.388 & 6.224 & 7.041 & 7.764 & 8.467 \\
\hline 76.242 & 6.309 & 0.193 & 1.179 & 3.931 & 4.711 & 5.478 & 6.309 & 7.120 & 7.836 & 8.532 \\
\hline 77.273 & 6.394 & 0.189 & 1.195 & 4.026 & 4.804 & 5.568 & 6.394 & 7.199 & 7.909 & 597 \\
\hline 78.303 & 6.479 & 0.185 & 1.212 & 4.119 & 4.896 & 5.657 & 6.479 & 7.278 & 7.982 & 8.664 \\
\hline 79.333 & 6.564 & 0.182 & 1.228 & 4.213 & 4.988 & 5.747 & 6.564 & 7.358 & 8.056 & 8.732 \\
\hline 80.364 & 6.648 & 0.178 & 1.244 & 4.305 & 5.080 & 5.836 & 6.649 & 7.438 & 8.131 & 8.801 \\
\hline 81.394 & 6.733 & 0.175 & 1.261 & 4.398 & 5.171 & 5.924 & 6.733 & 7.518 & 8.206 & 8.871 \\
\hline 82.424 & 6.818 & 0.172 & 1.277 & 4.489 & 5.261 & 6.013 & 6.818 & 7.598 & 8.282 & 8.941 \\
\hline 83.455 & 6.903 & 0.169 & 1.293 & 4.581 & 5.352 & 6.101 & 6.903 & 7.679 & 8.358 & 9.012 \\
\hline 84.485 & 6.988 & 0.166 & 1.310 & 4.672 & 5.442 & 6.189 & 6.988 & 7.760 & 8.434 & 9.084 \\
\hline 85.515 & 7.073 & 0.164 & 1.326 & 4.762 & 5.532 & 6.277 & 7.073 & 7.841 & 8.511 & 9.157 \\
\hline 86.545 & 7.158 & 0.161 & 1.342 & 4.852 & 5.621 & 6.365 & 7.158 & 7.922 & 8.589 & 9.230 \\
\hline 87.576 & 7.243 & 0.159 & 1.359 & 4.942 & 5.711 & 6.453 & 7.243 & 8.004 & 8.667 & 9.303 \\
\hline 88.606 & 7.328 & 0.156 & 1.375 & 5.032 & 5.800 & 6.541 & 7.328 & 8.085 & 8.744 & 9.377 \\
\hline 89.636 & 7.413 & 0.154 & 1.391 & 5.122 & 5.889 & 6.628 & 7.413 & 8.167 & 8.823 & 9.452 \\
\hline 90.667 & 7.498 & 0.151 & 1.408 & 5.212 & 5.978 & 6.716 & 7.498 & 8.249 & 8.901 & 9.526 \\
\hline 91.697 & 7.583 & 0.149 & 1.424 & 5.301 & 6.067 & 6.803 & 7.583 & 8.330 & 8.979 & 9.601 \\
\hline 92.727 & 7.668 & 0.147 & 1.440 & 5.391 & 6.156 & 6.891 & 7.668 & 8.412 & 9.058 & 9.676 \\
\hline 93.758 & 7.753 & 0.145 & 1.456 & 5.481 & 6.245 & 6.978 & 7.753 & 8.494 & 9.137 & 9.752 \\
\hline 94.788 & 7.838 & 0.143 & 1.473 & 5.571 & 6.334 & 7.065 & 7.838 & 8.576 & 9.216 & 9.827 \\
\hline 95.818 & 7.923 & 0.141 & 1.489 & 5.661 & 6.423 & 7.153 & 7.923 & 8.658 & 9.295 & 9.902 \\
\hline 96.848 & 8.008 & 0.139 & 1.505 & 5.751 & 6.512 & 7.240 & 8.008 & 8.740 & 9.373 & 9.978 \\
\hline 97.879 & 8.093 & 0.137 & 1.522 & 5.841 & 6.602 & 7.328 & 8.093 & 8.822 & 9.452 & 10.053 \\
\hline 98.909 & 8.178 & 0.135 & 1.538 & 5.932 & 6.691 & 7.415 & 8.178 & 8.904 & 9.531 & 10.129 \\
\hline 99.939 & 8.263 & 0.133 & 1.554 & 6.023 & 6.781 & 7.503 & 8.263 & 8.986 & 9.610 & 10.204 \\
\hline 100.970 & 8.348 & 0.131 & 1.571 & 6.114 & 6.870 & 7.591 & 8.348 & 9.068 & 9.689 & 10.280 \\
\hline 102.000 & 8.433 & 0.129 & 1.587 & 6.206 & 6.960 & 7.678 & 8.433 & 9.149 & 9.767 & 10.355 \\
\hline
\end{tabular}

Appendix 4: The lambda, sigma, and mu values for the centiles modelled for all height classes where " $\mathrm{x}$ " is age in years and " $\mathrm{P}$ " is percentile.

All Classes

\begin{tabular}{lllllllllll}
\hline $\mathbf{x}$ & mu & sigma & nu & P3 & P10 & P25 & P50 & P75 & P90 & P97 \\
\hline 0.000 & 0.022 & 0.554 & -0.395 & 0.009 & 0.012 & 0.015 & 0.022 & 0.032 & 0.050 & 0.083 \\
0.778 & 0.055 & 0.556 & -0.372 & 0.023 & 0.029 & 0.039 & 0.055 & 0.083 & 0.127 & 0.208 \\
1.556 & 0.089 & 0.558 & -0.349 & 0.036 & 0.047 & 0.063 & 0.089 & 0.134 & 0.203 & 0.330
\end{tabular}




\begin{tabular}{|c|c|c|c|c|c|c|c|c|c|c|}
\hline 3 & 123 & 560 & -0.326 & 0.050 & 0.065 & 0.086 & 0.123 & 0.185 & 280 & \\
\hline 111 & 158 & 563 & & .063 & & & & & .356 & \\
\hline 889 & .192 & .565 & -0.280 & & 0.100 & 0.134 & & 288 & & 680 \\
\hline 667 & & & & & & & & & 10 & \\
\hline & & & & & & & & & & \\
\hline & & & & & & & & & & \\
\hline .000 & 341 & & & & & & & & & \\
\hline 7.778 & 382 & 578 & & .141 & .190 & & & 71 & 341 & 265 \\
\hline 8.556 & .425 & 580 & 43 & 154 & .210 & .290 & 425 & & 932 & 391 \\
\hline 333 & .470 & 583 & 20 & 168 & .230 & 320 & 470 & 703 & 028 & 522 \\
\hline 111 & .518 & & & & & & & & & 558 \\
\hline 889 & 0.568 & 88 & & & & & & & & 799 \\
\hline & 021 & 590 & & & & & & & & \\
\hline & & & & & & & & & & \\
\hline & c & & & & & & & & & \\
\hline .000 & 0.796 & 595 & & & 369 & & & & & .412 \\
\hline .778 & 0.860 & 596 & 0.041 & 0.273 & 0.396 & 0.573 & .860 & 1.282 & 826 & .575 \\
\hline 556 & 0.927 & 597 & 064 & 289 & 423 & & 927 & & 57 & 742 \\
\hline 333 & 996 & 598 & 087 & 305 & 451 & & & & & 911 \\
\hline & .067 & & & & & & & & & 082 \\
\hline & 1.141 & & & & & & & & & \\
\hline 667 & 1.217 & & & & & & & & & $4<4$ \\
\hline & & & & & & & & & & \\
\hline & & & & & & & & & & \\
\hline .000 & 1457 & 592 & & & & 959 & & & & 932 \\
\hline .778 & 1.539 & & & & & & & & & 097 \\
\hline & 1.624 & & & & & & & & & 258 \\
\hline .333 & 1.709 & .582 & & & 0.736 & & & & & .416 \\
\hline 111 & 1.794 & 578 & 17 & .473 & 771 & 83 & & 92 & 92 & 1.570 \\
\hline 889 & 1.880 & & & & & & & & & 719 \\
\hline 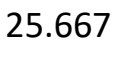 & & & & & & & & & & 003 \\
\hline & & & & & & & & & & 3.002 \\
\hline & & & & & & & & & & 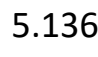 \\
\hline & & & & & & & & & & \\
\hline & 2.310 & & & & 0.990 & & & & & 5.386 \\
\hline 9.556 & 2.394 & 0.543 & & 0.590 & 1.027 & 1.600 & 2.394 & 3.356 & & 5.502 \\
\hline 30.333 & 2.477 & 0.538 & 0.500 & 0.606 & 1.065 & & 2.477 & 3.456 & 4.476 & 5.613 \\
\hline 1.111 & 2.558 & 532 & & & & & & & & 5.717 \\
\hline 31.889 & 2.637 & & & & & & & & 681 & 5.815 \\
\hline 2.001 & 2.715 & & & & & & & & & 5.908 \\
\hline 33.444 & 2.790 & 0.514 & 0.592 & 0.670 & 1.213 & 1.894 & 2.791 & 3.826 & 4.868 & 5.994 \\
\hline
\end{tabular}




\begin{tabular}{|c|c|c|c|c|c|c|c|c|c|c|}
\hline & 864 & & & & & & & & & \\
\hline .000 & 935 & .503 & 638 & 0.700 & 1.285 & 2.006 & 2.937 & 3.990 & 5.035 & 150 \\
\hline & 004 & 497 & 561 & 716 & .321 & 2.060 & 3.006 & .067 & 112 & 220 \\
\hline & & 491 & & & & & & & 84 & 285 \\
\hline & 133 & 486 & 07 & 745 & 389 & 164 & & 10 & 252 & 344 \\
\hline L1 & 194 & .481 & 730 & 760 & .423 & .213 & 199 & .277 & 316 & 399 \\
\hline & & & & 0.774 & & 62 & & & & 44 \\
\hline & 309 & & & & & & & & & \\
\hline & & 0.466 & & & & & & & & 530 \\
\hline & & .462 & & & & & & & & \\
\hline & & & & & & & & & & 612 \\
\hline & .508 & .453 & 868 & 839 & .603 & 2.479 & & & & 641 \\
\hline 3.556 & .552 & 0.449 & 891 & 0.852 & 1.630 & 2.518 & 3.565 & 4.653 & .659 & 673 \\
\hline .333 & 594 & 0.445 & 914 & 0.863 & 656 & 2.555 & 3.608 & 4.696 & & 70 \\
\hline 11 & 634 & .442 & 937 & 0.875 & 1.681 & .591 & 50 & & 731 & 725 \\
\hline & 72 & 39 & & & 1.705 & 2.626 & & & & 748 \\
\hline & & & & & .729 & & & & & 709 \\
\hline & 743 & 432 & & & 752 & & & & & \\
\hline & & & & & & & & & & \\
\hline & & & & & & & & & & \\
\hline 9.778 & .837 & .424 & & 942 & .816 & & & & & 835 \\
\hline .556 & .866 & 0.421 & 098 & 0.953 & .837 & 2.810 & & & 922 & 848 \\
\hline & 894 & 419 & & 965 & .857 & 2.837 & & & & 860 \\
\hline & 920 & & & & 877 & & & & & 87 \\
\hline & 946 & .414 & & & 1.897 & 2.891 & & & & 881 \\
\hline 67 & .970 & 412 & & .000 & 1.917 & 2.917 & & & & 0. \\
\hline & & & & & & & & & & \\
\hline & .018 & & & & & & & & & \\
\hline & & & & & & & & & & \\
\hline & .063 & & & & 1.997 & & & & & \\
\hline & 085 & .402 & & 066 & .017 & 3.042 & .143 & 86 & & 929 \\
\hline 3.333 & 108 & .400 & 327 & .080 & .037 & 3.067 & 4.169 & 5.208 & 96 & .937 \\
\hline 59.111 & 130 & 398 & 350 & 095 & .058 & 3.092 & 4.194 & 5.230 & 113 & .945 \\
\hline 59.889 & .152 & 396 & & & 079 & & 4.220 & 252 & & 955 \\
\hline .667 & 175 & 0.394 & & & 2.100 & & & & & .965 \\
\hline 1.444 & 198 & 0.392 & & & 2.121 & 3.168 & & & & \\
\hline 2.222 & .221 & & & & & & & & & \\
\hline & & & & & & & & & & \\
\hline & 4.269 & & & & & & & & & \\
\hline & 4.293 & & & 1.210 & & & & & 6.245 & 032 \\
\hline & 4.318 & 0.384 & 1.534 & 1.228 & 2.235 & 3.303 & 4.411 & 5.424 & 6.267 & 7.02 \\
\hline
\end{tabular}




\begin{tabular}{lllllllllll}
66.111 & 4.343 & 0.383 & 1.557 & 1.247 & 2.259 & 3.331 & 4.440 & 5.451 & 6.290 & 7.066 \\
66.889 & 4.369 & 0.381 & 1.580 & 1.266 & 2.284 & 3.359 & 4.470 & 5.478 & 6.314 & 7.085 \\
67.667 & 4.395 & 0.380 & 1.603 & 1.285 & 2.309 & 3.388 & 4.500 & 5.506 & 6.338 & 7.104 \\
68.444 & 4.421 & 0.379 & 1.626 & 1.305 & 2.334 & 3.417 & 4.530 & 5.535 & 6.363 & 7.124 \\
69.222 & 4.448 & 0.377 & 1.649 & 1.325 & 2.359 & 3.447 & 4.560 & 5.563 & 6.388 & 7.145 \\
70.000 & 4.475 & 0.376 & 1.672 & 1.345 & 2.385 & 3.476 & 4.591 & 5.592 & 6.413 & 7.165 \\
70.778 & 4.501 & 0.374 & 1.695 & 1.366 & 2.411 & 3.506 & 4.622 & 5.621 & 6.439 & 7.186 \\
71.556 & 4.528 & 0.373 & 1.718 & 1.387 & 2.438 & 3.536 & 4.653 & 5.650 & 6.464 & 7.208 \\
72.333 & 4.555 & 0.372 & 1.741 & 1.409 & 2.464 & 3.566 & 4.684 & 5.679 & 6.490 & 7.229 \\
73.111 & 4.582 & 0.370 & 1.764 & 1.431 & 2.491 & 3.596 & 4.715 & 5.708 & 6.516 & 7.251 \\
73.889 & 4.610 & 0.369 & 1.787 & 1.453 & 2.518 & 3.627 & 4.746 & 5.737 & 6.542 & 7.273 \\
74.667 & 4.637 & 0.367 & 1.810 & 1.475 & 2.546 & 3.657 & 4.777 & 5.766 & 6.568 & 7.294 \\
75.444 & 4.664 & 0.366 & 1.833 & 1.498 & 2.573 & 3.687 & 4.808 & 5.795 & 6.594 & 7.316 \\
76.222 & 4.691 & 0.365 & 1.856 & 1.521 & 2.601 & 3.718 & 4.838 & 5.824 & 6.619 & 7.338 \\
77.000 & 4.718 & 0.363 & 1.879 & 1.544 & 2.628 & 3.748 & 4.869 & 5.853 & 6.645 & 7.360 \\
\hline
\end{tabular}

Appendix 5: Statistical output produced by RefCurve for the best fitting model for height class 1.

\begin{tabular}{ll|rrrr}
\hline & & Estimate & Std. Error & t-value & $\operatorname{Pr}(>|\mathbf{t}|)$ \\
\hline Mu Coeff. & Intercept & 0.00534 & 0.00107 & 4.99 & $6.46 \mathrm{E}-07$ \\
& $\mathbf{p b}(\mathbf{x}$, median df) & 0.04024 & 0.00042 & 95.69 & $<2.00 \mathrm{E}-16$ \\
\hline Sigma Coeff. & Intercept & -0.5439 & 0.0268 & -20.3 & $<2.00 \mathrm{E}-16$ \\
& pb(x, sigma df) & -0.0118 & 0.00144 & -8.195 & $4.00 \mathrm{E}-16$ \\
\hline Nu Coeff. & Intercept & -0.3812 & 0.05125 & -7.439 & $1.40 \mathrm{E}-13$ \\
& pb(x, nu df) & 0.02193 & 0.00333 & 6.589 & $5.40 \mathrm{E}-11$ \\
\hline
\end{tabular}

Appendix 6: Statistical output produced by RefCurve for the best fitting model for height class 2.

\begin{tabular}{ll|rrrr}
\hline & & Estimate & Std. Error & t-value & $\operatorname{Pr}(>|\mathbf{t}|)$ \\
\hline Mu Coeff. & Intercept & -0.0456 & 0.00109 & -41.98 & $<2.00 \mathrm{E}-16$ \\
& $\mathbf{p b}(\mathbf{x}$, median df) & 0.07686 & 0.00051 & 151.25 & $<2.00 \mathrm{E}-16$ \\
\hline Sigma Coeff. & Intercept & -0.5698 & 0.02307 & -24.7 & $<2.00 \mathrm{E}-16$ \\
& $\mathbf{p b}(\mathbf{x}$, sigma df) & -0.0122 & 0.00106 & -11.5 & $<2.00 \mathrm{E}-16$ \\
\hline Nu Coeff. & Intercept & -0.6229 & 0.05077 & 22.34 & $<2.00 \mathrm{E}-16$ \\
& $\mathbf{p b}(\mathbf{x}, \mathbf{n u} \mathbf{d f})$ & 0.05885 & 0.00263 & 22.34 & $<2.00 \mathrm{E}-16$ \\
\hline
\end{tabular}


Appendix 7: Statistical output produced by RefCurve for the best fitting model for height class 3.

\begin{tabular}{ll|rrrr}
\hline & & Estimate & Std. Error & t-value & $\operatorname{Pr}(>|\mathbf{t}|)$ \\
\hline Mu Coeff. & Intercept & 0.02118 & 0.00137 & 15.42 & $<2.00 \mathrm{E}-16$ \\
& $\mathbf{p b}(\mathbf{x}$, median df) & 0.08247 & 0.00063 & 131.86 & $<2.00 \mathrm{E}-16$ \\
\hline Sigma Coeff. & Intercept & -0.2755 & 0.0208 & -13.25 & $<2.00 \mathrm{E}-16$ \\
& $\mathbf{p b}(\mathbf{x}$, sigma df) & -0.0144 & 0.0006 & -23.98 & $<2.00 \mathrm{E}-16$ \\
\hline Nu Coeff. & Intercept & -0.028 & 0.04319 & -0.649 & $5.16 \mathrm{E}-01$ \\
& $\mathbf{p b}(\mathbf{x}, \mathbf{n u} \mathbf{d f})$ & 0.01583 & 0.00188 & 8.422 & $<2.00 \mathrm{E}-16$ \\
\hline
\end{tabular}

Appendix 8: Statistical output produced by RefCurve for the best fitting model for all height classes.

\begin{tabular}{ll|rrrc}
\hline & & Estimate & Std. Error & t-value & $\operatorname{Pr}(>|\mathbf{t}|)$ \\
\hline Mu Coeff. & Intercept & -0.2157 & 0.00069 & -310.6 & $<2.00 \mathrm{E}-16$ \\
& $\mathbf{p b}(\mathbf{x}$, median df) & 0.08849 & 0.00037 & 236.9 & $<2.00 \mathrm{E}-16$ \\
\hline Sigma Coeff. & Intercept & -0.4694 & 0.01284 & -36.55 & $<2.00 \mathrm{E}-16$ \\
& pb(x, sigma df) & -0.0064 & 0.00051 & -12.42 & $<2.00 \mathrm{E}-16$ \\
\hline Nu Coeff. & Intercept & -0.3953 & 0.02664 & -14.84 & $<2.00 \mathrm{E}-16$ \\
& pb(x, nu df) & 0.02953 & 0.00131 & 22.59 & $<2.00 \mathrm{E}-16$ \\
\hline
\end{tabular}

